\title{
Circuit Mechanisms Underlying the Segregation and Integration of Parallel Processing Streams in the Inferior Colliculus
}

\author{
Alexandria M.H. Lesicko, ${ }^{1,2}$ Stacy K. Sons, ${ }^{2,3}$ and ${ }^{\circledR}$ Daniel A. Llano ${ }^{1,2,3}$ \\ ${ }^{1}$ Neuroscience Program, University of Illinois at Urbana-Champaign, Urbana, IL 61801, ${ }^{2}$ Beckman Institute for Advanced Science and Technology, \\ University of Illinois at Urbana-Champaign, Urbana, IL 61801, and ${ }^{3}$ Department of Molecular and Integrative Physiology, University of Illinois at \\ Urbana-Champaign, Urbana, IL 61801
}

The lateral cortex of the inferior colliculus (LCIC) forms a nexus between diverse multisensory, motor, and neuromodulatory streams. Like other integration hubs, it contains repeated neurochemical motifs with distinct inputs: GABA-rich modules are innervated by somatosensory structures, while auditory inputs to the LCIC target the surrounding extramodular matrix. To investigate potential mechanisms of convergence between these input streams, we used laser photostimulation circuit mapping to interrogate local LCIC circuits in adult mice of both sexes and found that input patterns are highly dependent on cell type (GABAergic/non-GABAergic) and location (module/matrix). At the circuit level, these inputs yield a directional flow of local information, primarily from the matrix to the modules. Further, the two compartments were found to project to distinct targets in the midbrain and thalamus. These data show that, while connectional modularity in the LCIC gives rise to segregated input-output channels, local circuits provide the architecture for integration between these two streams.

Key words: auditory; colliculus; module; photostimulation; somatosensory; thalamus

\section{Significance Statement}

Modularity is a widespread motif across the brain involving the segregation of structures into discrete subregions based on dichotomies in neurochemical expression or connectivity. The inferior colliculus is one such modular structure, containing auditory-recipient matrix regions and GABA-rich modules that are innervated by somatosensory inputs. While modularity suggests segregation of processing streams, here we show that local circuits in the inferior colliculus connect the module and matrix regions, providing an avenue for integration of information across compartments.

\section{Introduction}

A number of brain regions can be parcellated at the subnuclear level based on differences in neurochemistry, cytoarchitecture, or connectivity. The most heavily studied of these "modular" structures include the somatosensory barrel cortex and the patch/matrix organization of the striatum (Gerfen, 1992; Petersen, 2007). The inferior colliculus (IC), a midbrain structure that is centrally positioned within the auditory system and thought to serve as

\footnotetext{
Received Mar. 18, 2020; revised June 28, 2020; accepted July 4, 2020.

Author contributions: A.M.H.L., S.K.S., and D.A.L. designed research; A.M.H.L. and S.K.S. performed research; A.M.H.L. and D.A.L. analyzed data; A.M.H.L. wrote the paper; D.A.L. edited the paper.

This work was supported by F31 DC 015967 to A.M.H.L. and R01 DC 013073 from the National Institute on Deafness and Other Communication Disorders at the National Institutes of Health to D.A.L. We thank Dr. Doug Oliver for providing the GAD-GFP mouse strain used in this study; Dr. Yuchio Yanagawa for permission to use the GAD-GFP mouse strain used in this study; and Diana Masolak and Danica Vendiola for technical assistance with tissue processing.

The authors declare no competing financial interests.

Correspondence should be addressed to Daniel A. Llano at d-llano@illinois.edu.

https://doi.org/10.1523/JNEUROSCI.0646-20.2020

Copyright $\odot 2020$ the authors
}

an integration hub for acoustic information, also exhibits neurochemical and structural modularity (Casseday et al., 2002). Specifically, the lateral cortex of the IC (LCIC) can be subdivided into modular regions ("modules") characterized by dense staining for glutamic acid decarboxylase-67, parvalbumin, cytochrome oxidase, acetylcholinesterase, and NADPH-diaphorase, and extramodular regions (termed "matrix") that are characterized by heavy calretinin labeling (Chernock et al., 2004; Stebbings et al., 2014; Lesicko et al., 2016; Dillingham et al., 2017).

These neurochemical divisions also correlate with differences in connectivity: somatosensory inputs target LCIC modules, whereas matrix regions receive auditory inputs from the auditory cortex (AC) and central nucleus of the IC (CNIC) (Lesicko et al., 2016). An unresolved paradox exists in this arrangement of multimodal inputs: the apparent anatomic segregation in somatosensory and auditory inputs belies a long history of physiological studies demonstrating multisensory convergence in the LCIC. Early recordings from the cat LCIC discovered single units that respond to both auditory and somatosensory stimuli (Aitkin et 
al., 1978, 1981). Other studies that have examined the effect of spinal trigeminal nucleus or dorsal column stimulation on responses to sound in the LCIC have found that the majority of units respond bimodally (Aitkin et al., 1978; Jain and Shore, 2006).

Given the evidence for the role of the LCIC in multisensory integration, it is peculiar that the somatosensory and auditory inputs to the LCIC are spatially segregated. This lack of convergence among multisensory inputs to the LCIC suggests that a secondary mechanism of integration must be present: either information from the two senses is integrated in a lower structure that projects to the LCIC, or there is communication between local circuits in module and matrix regions of the LCIC. In the present study, we specifically investigate the latter possibility through functional characterization of the local inputs to LCIC neurons. To further elucidate the extent and potential role of connectional modularity in the LCIC, we also use retrograde tract-tracing to determine whether the compartments of the LCIC send information to distinct targets.

\section{Materials and Methods}

Animals. Juvenile (postnatal day 11-21) and adult (postnatal day 3090) glutamic acid decarboxylase-67 (GAD67)-GFP knock-in mice of both sexes were used for laser photostimulation and anatomy studies, respectively. Knock-in mice were initially obtained from the University of Connecticut and were bred with WT Swiss Webster mice to generate hemizygous progeny in which enhanced GFP is under control of the endogenous GAD67 promoter (Tamamaki et al., 2003; Ono et al., 2005). Previous work has shown that immunostaining for GABA or GAD colocalizes with GFP in these mice (Tamamaki et al., 2003; Gay et al., 2018). Animals were screened for phenotypic evidence of transgene expression between postnatal day 2 and 7 . The screening procedure involved illuminating the dorsal surface of the scalp with blue light (the excitation range for GFP) and checking for evidence of green fluorescence in the cortex, midbrain, and cerebellum. All procedures were approved by the Institutional Animal Care and Use Committee at the University of Illinois. Animals were housed in care facilities approved by the American Association for Assessment and Accreditation of Laboratory Animal Care. Every attempt was made to minimize the number of animals used and to reduce suffering at all stages of the study.

Slice preparation. Mice were anesthetized with a mixture of ketamine hydrochloride $(100 \mathrm{mg} / \mathrm{kg})$ and xylazine $(3 \mathrm{mg} / \mathrm{kg})$ and perfused transcardially with a cold slicing solution containing the following: $206 \mathrm{~mm}$ sucrose, $10 \mathrm{~mm} \mathrm{MgCl}$, $11 \mathrm{~mm}$ glucose, $1.25 \mathrm{~mm} \mathrm{NaH} \mathrm{PO}_{4}, 26 \mathrm{~mm}$ $\mathrm{NaHCO}_{3}, 0.5 \mathrm{~mm} \mathrm{CaCl}_{2}, 2.5 \mathrm{~mm} \mathrm{KCl}$, and $1 \mathrm{~mm}$ kynurenic acid, pH 7.4. The brain was removed, and 300- $\mu \mathrm{m}$-thick coronal tissue slices throughout the IC were obtained using a vibratome. The slices were transferred to an incubation solution ( $126 \mathrm{~mm} \mathrm{NaCl}, 3 \mathrm{~mm} \mathrm{MgCl}_{2}, 10 \mathrm{~mm}$ glucose, $\left.1.25 \mathrm{~mm} \mathrm{NaH}_{2} \mathrm{PO}_{4}, 26 \mathrm{~mm} \mathrm{NaHCO}_{3}, 1 \mathrm{~mm} \mathrm{CaCl}_{2}, 2.5 \mathrm{~mm} \mathrm{KCl}, \mathrm{pH} 7.4\right)$ and warmed to $32^{\circ} \mathrm{C}$ for $1 \mathrm{~h}$ before recording.

Electrophysiology. Tissue slices containing the LCIC were transferred to a recording chamber and submerged in an oxygenated ACSF solution containing the following: $126 \mathrm{mM} \mathrm{NaCl}, 2 \mathrm{~mm} \mathrm{MgCl}, 10 \mathrm{~mm}$ glucose, $1.25 \mathrm{~mm} \mathrm{NaH}_{2} \mathrm{PO}_{4}, 26 \mathrm{~mm} \mathrm{NaHCO}, 2 \mathrm{~mm} \mathrm{CaCl}, 2.5 \mathrm{KCl}, \mathrm{pH}$ 7.4. Modular and matrix regions of the LCIC were identified through differential expression of GAD67-GFP under blue illumination. Cells were categorized into four groups based on whether they were found in module or matrix regions of the LCIC and whether they were $\mathrm{GAD}^{+} 7^{+}$or GAD67 ${ }^{-}$. After identification of cell type, neurons were recorded in either a single or dual whole-cell configuration using Cs-gluconate (117 mM Cs-gluconate, $13 \mathrm{~mm} \mathrm{CsCl,} 1 \mathrm{~mm} \mathrm{MgCl}_{2}, 0.07 \mathrm{mM} \mathrm{CaCl}_{2}, 0.1 \mathrm{~mm}$ EGTA, 10 mм HEPES, $2 \mathrm{~mm} \mathrm{Na}_{2}$-ATP, $0.4 \mathrm{~mm} \mathrm{Na-GTP)} \mathrm{filled} \mathrm{pipettes}$ with tip resistances of 4-7 $\mathrm{M} \Omega$. Both AlexaFluor-594 hydrazide (Thermo Fisher Scientific, \#A10438; $7 \mu \mathrm{M}$ ) and biocytin (Sigma Millipore, \#B4261; $4 \mathrm{~mm}$ ) were added to the internal solution to aid in morphologic reconstruction and post hoc confirmation of cell location. Data were acquired using a Multiclamp 700B amplifier and Digidata 1440A digitizer at a sampling rate of $20 \mathrm{kHz}$ in pClamp software (Molecular Devices). Cells were held in voltage clamp at $-60 \mathrm{mV}$ and $+10 \mathrm{mV}$ to isolate excitatory and inhibitory currents, respectively, and traces were filtered with a $1 \mathrm{kHz}$ Bessel filter to remove noise.

Laser photostimulation. MNI-caged-L-glutamate (Tocris Bioscience, \#1490) was added to recirculating ACSF at a concentration of $150 \mu \mathrm{M}$ and focally photolysed by a pulsed $355 \mathrm{~nm}$ laser ( $1 \mathrm{~ms}$ pulses). The power of the laser beam at slice level was measured and maintained at $3 \mathrm{~mW}$ for all experiments. The laser beam was directed into the side port of an Olympus microscope using UV-enhanced aluminum mirrors and a pair of mirror galvanometers and then focused onto the brain slice using a $10 \times$ objective. Angles of the galvanometers were computer-controlled using PrairieView software (Prairie Technologies). The Q-switch of the laser and a shutter controlled the timing of the laser pulse for stimulation. The stimulation pattern for input mapping consisted of 200 positions arranged in a $10 \times 20$ array, with $80 \mu \mathrm{m}$ between adjacent rows and columns (see Fig. 1C). A non-neighbor stimulation paradigm in which sequentially stimulated sites are spatially dispersed was used to prevent local accumulation of uncaged glutamate and desensitization of receptors following repeated stimulation (Shepherd et al., 2003). Excitatory and inhibitory maps were repeated 2-3 times each and averaged to ensure consistent results and reduce the effect of spontaneous inputs. To distinguish between direct activation of the recorded cell and synaptic activation of presynaptic partners, the excitatory mapping was repeated in low-calcium ACSF $(126 \mathrm{~mm} \mathrm{NaCl}, 4 \mathrm{~mm} \mathrm{MgCl} 2,10 \mathrm{~mm}$ glucose, $1.25 \mathrm{~mm} \mathrm{NaH} \mathrm{PO}_{4}, 26 \mathrm{~mm} \mathrm{NaHCO}, 0.2 \mathrm{~mm} \mathrm{CaCl}, 2.5 \mathrm{KCl}$, pH 7.4) to block synaptic activity, and this "direct" input map was subtracted from the original excitatory map to generate a map containing only excitatory synaptic inputs (Llano and Sherman, 2009; Slater et al., 2019) (see Fig. 1D).

Excitation profiles. Excitation mapping was performed to determine how photostimulation at specific experimental parameters $(3 \mathrm{~mW}, 1 \mathrm{~ms}$ laser pulses) affects the spike output of each of the four cell types of interest. Cells were recorded from in cell-attached mode, and a $10 \times 10$ grid with $20 \mu \mathrm{m}$ between adjacent stimulation sites was centered over the soma. For each cell, the mapping was repeated 4 times, and the total number of spikes in the average map was compared to determine whether differences in excitability exist between cell types (Fig. 1E). The average number of spikes at various distances from the soma was also computed to determine the approximate width of activation for a single laser pulse (Fig. $1 G$ ). The spike output for all cells plateaued at distances further than $80 \mu \mathrm{m}$, with an average spike output of $<1$ spike per stimulation site (Fig. $1 G$ ). This spacing was therefore used for all mapping experiments throughout the rest of the study to maximize the likelihood that each laser stimulus samples distinct populations of cells.

Tracer injection. Mice were anesthetized intraperitoneally with a mixture of ketamine hydrochloride $(100 \mathrm{mg} / \mathrm{kg})$ and xylazine $(3 \mathrm{mg} / \mathrm{kg})$, and a small hole was drilled in the skull above the structure of interest. A glass micropipette, tip diameter $20-30 \mu \mathrm{m}$, was filled with a $2 \%$ solution of Fluoro-Gold (FG) dissolved in acetate buffer (pH 3.3) and lowered into the brain. FG was injected iontophoretically using $5 \mu \mathrm{A}$ positive current pulses (50\% duty cycle) for $10-20 \mathrm{~min}$. A $15 \mu \mathrm{A}$ negative holding current was applied during placement and removal of the pipette to prevent unwanted leakage of the tracer.

Tissue processing and microscopy. After recording, slices containing biocytin-filled cells were fixed overnight in a solution of $4 \%$ paraformaldehyde (PFA). Slices were rinsed 3 times in phosphate-buffered saline (PBS) and transferred to a solution containing $0.3 \%$ Triton X-100 and AlexaFluor-568-conjugated streptavidin (\#S-11226, Thermo Fisher Scientific). To visualize cell morphology, slices were wet-mounted on coverslips and imaged using an SP8 laser scanning confocal microscope (Leica Microsystems) and LAS X control software. Mosaic $z$ stacks were taken at $20 \times$ throughout the extent of the LCIC, collapsed into 2D maximum intensity projections, and tiled into a single image.

Following a 3-7 d survival period, FG-injected animals were anesthetized with a mixture of ketamine hydrochloride $(100 \mathrm{mg} / \mathrm{kg})$ and xylazine $(3 \mathrm{mg} / \mathrm{kg})$ and perfused transcardially with $4 \%$ PFA in PBS. The brain was removed and postfixed overnight in the PFA solution. After 

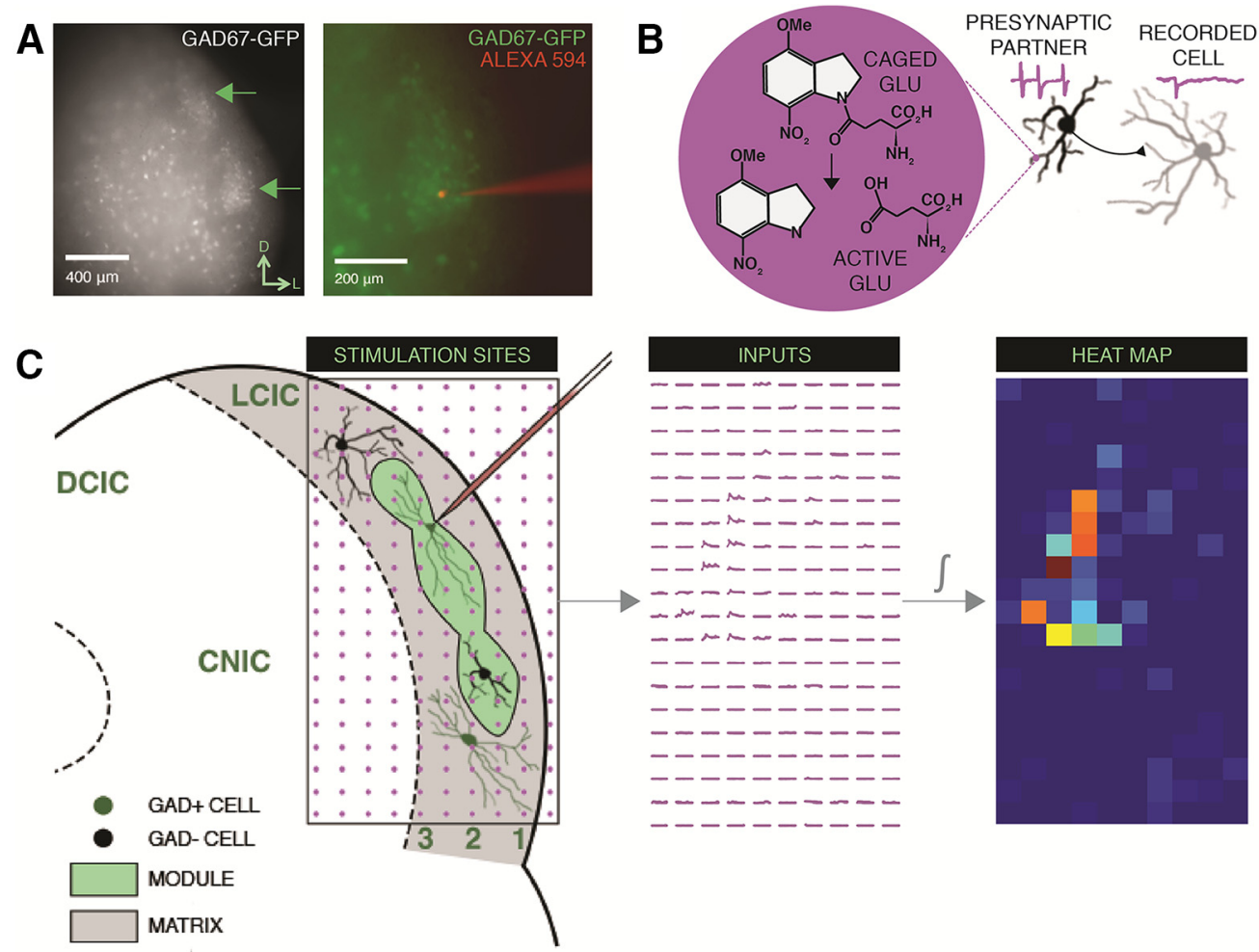

STIMULATION SITES
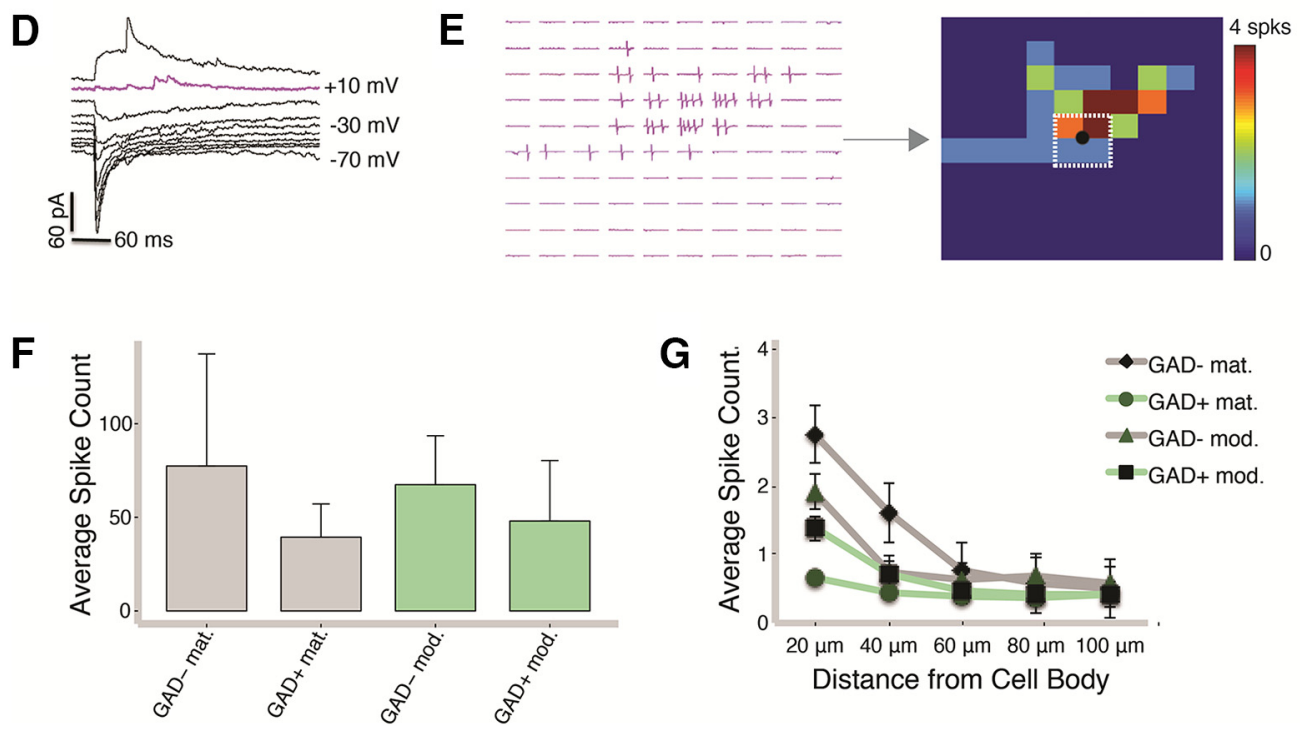

Figure 1. Experimental design. $\boldsymbol{A}$, Experiments were performed in tissue slices from the GAD67-GFP mouse in which modules are visually distinguishable under blue illumination. Cells were voltage-clamped at -60 and $+10 \mathrm{mV}$ to isolate excitatory and inhibitory inputs, respectively. $\boldsymbol{B}$, In focal regions of UV laser activation, caged glutamate is converted to active glutamate, thus generating spikes in presynaptic partners and postsynaptic currents in the recorded cell. C, Four groups of cells in the LCIC were recorded from GAD67+ (putative inhibitory) and GAD67- (putative excitatory) cells from both the modular and matrix regions. A $10 \times 20$ grid of stimulation sites was centered over the LCIC, and potential presynaptic partners were stimulated in a nonneighbor fashion. Responses were plotted according to the location from which they were generated and converted into heat maps by computing the area under the curve of each response. $\boldsymbol{D}$, Responses to photostimulation at various holding potentials. Note the presence of inward current at $0 \mathrm{mV}$ and the absence at $+10 \mathrm{mV}$. $\boldsymbol{E}$, Left, Example of spikes recorded in cell-attached mode in response to laser photostimulation ( $1 \mathrm{~ms}$ pulses, $3 \mathrm{~mW}$ ) at various locations (10 $\times 10$ grid, $20 \mu \mathrm{m}$ between adjacent rows and columns) near the cell body. Right, Spike output $100 \mathrm{~ms}$ after laser onset shown as a heat map. Black represents the location of the recorded cell. White outline indicates the $20 \mu \mathrm{m}$ radius used to generate the first bin shown in $\boldsymbol{G}$. $\boldsymbol{F}$, The total number of spikes (average of four trials) was computed for each cell and compared across cell types. No statistically significant differences were found across cell types (Kruskal-Wallis test, $p=0.84)$. $\mathbf{G}$, The average number of spikes elicited at various distances from the cell body was calculated and compared for each cell type (GAD- matrix: mean $=77.41$ spikes, median $=29, \mathrm{SD}=103.73, \mathrm{SEM}=59.89, \mathrm{Cl}= \pm 257.67, n=3$ cells; GAD + matrix: mean $=39.39$, median $=33.5, \mathrm{SD}=30.76, \mathrm{SEM}=17.76, \mathrm{Cl}= \pm 76.41, n=4$ cells; GAD- module: mean $=67.42$, median $=84.75, \mathrm{SD}=45.31, \mathrm{SEM}=26.16, \mathrm{Cl}= \pm 112.55, n=3$ cells; $\mathrm{GAD}+$ module: mean $=48$, median $=18.63, \mathrm{SD}=64.72, \mathrm{SEM}=32.36, \mathrm{Cl}= \pm 102.98, n=3$ cells).

being cryoprotected in an ascending series of sucrose solutions, the brain was embedded and cut into $40-\mu \mathrm{m}$-thick sections on a freezing sledge microtome. Tissue sections were imaged with an SP8 laser scanning confocal microscope (Leica Microsystems) and LAS X control software. FG and GFP were visualized separately using 405 and $488 \mathrm{~nm}$ excitation laser lines, respectively. Using these settings, images of each fluorophore were captured for each IC tissue section containing retrograde label, and $20 \times$ mosaic $z$ stacks were taken throughout the entire depth and $x-y$ 
plane of the IC. The stacks were collapsed into $2 \mathrm{D}$ maximum intensity projections and tiled into a single image using LAS $\mathrm{X}$ software. Composite images of the FG and GFP channels were overlaid, and Photoshop was used to adjust the color balance and to draw masks around the edge of the tissue to cover the embedding medium. Reconstructions and cell counts were performed using Neurolucida software. The Allen Reference Atlas was used to determine the location of injection sites (Goldowitz, 2010).

Analysis. Custom-written MATLAB scripts were used to quantify laser-driven responses. For a given cell, a trapezoidal integration function was applied to each trace to calculate the inhibitory and excitatory charge in the first $100 \mathrm{~ms}$ after laser onset. These values were then converted into heat maps. Images of GAD67-GFP fluorescence were parcellated into modules (high-pixel intensity regions in layer 2 of the LCIC) and matrix regions first using hand-drawn ROIs. These ROIs were then independently confirmed using clustering algorithms in the MATLAB Image Segmenter App. The location of the recorded cell was determined from images of AlexaFluor-594 hydrazide fluorescence overlaid with the GAD67-GFP images. Finally, heat maps were overlaid onto the fluorescence images, and each stimulation site was categorized as originating from either the module or matrix regions. The border between the LC and the CNIC was estimated by drawing a curved ROI extending orthogonally from the border of layer 2 (delineated as the medial-most edge of the modules) at a distance $1.5 \times$ the width of layer 2 . This ratio was determined from previous studies that have used histochemical approaches to determine the borders between LC and CNIC (Loftus et al., 2008). All CNIC and off-tissue stimulation sites were removed from the analysis. The charge from responses originating from each compartment was summed to yield the total inhibitory and excitatory synaptic charge arising from the module and matrix areas. To quantify the balance of input to individual cells from the module and matrix regions, a modularity index was computed as follows:

$$
\left(M \text { index }=\frac{\text { total charge from region containing cell body }- \text { total charge from opposite region }}{\text { total charge }}\right)
$$

Cells with a positive index receive more input from the region containing their soma (e.g., a cell located within a module receives more input from the modules than the matrix), cells with a negative index receive more input from the opposite region, and cells with an index near zero receive mixed input. Similarly, the balance of excitatory and inhibitory synaptic input for each cell was calculated using an E:I index as follows:

$$
\left(E: I \text { index }=\frac{\text { total excitatory } \text { charge }- \text { total inhibitory } \text { charge }}{\text { total charge }}\right)
$$

Two separate methods, a cross-correlation analysis and a correlation-coefficient analysis, were used to quantify the similarity between maps from simultaneously recorded cells. The cross-correlation analysis was derived from methods previously used to analyze paired recordings (Yoshimura and Callaway, 2005; Zarrinpar and Callaway, 2006), and involved taking a site-by-site cross-correlation of the photostimulation responses for each pair and generating a map of these values (see Fig. $5 B$, $C$, right). The average cross-correlation value of the entire map was computed to compare between different pair types (see Fig. 5D). The correlation-coefficient analysis was used to generate correlation coefficients (Fisher $z$-transformed) between total synaptic input at corresponding sites for each pair of maps (see Fig. $5 E$ ). The cross-correlation analysis method generates the largest values for pairs of cells having similar timecourses of synaptic inputs, while the correlation-coefficient analysis will yield largest values for cells with the largest spatial overlap of inputs, yielding complementary information.

Statistical procedures. Summary statistics, including the mean, median, SD, SEM, and 95\% CI, were computed for all measures. In all cases, statistical outliers were included in subsequent analysis. Shapiro-Wilk tests were used to determine whether the data were normally distributed.
In cases in which the assumption of normality was violated, KruskalWallis and Dunn's post hoc testing (with a Holm adjustment for multiple comparisons) were used to compare more than two groups, and Wilcoxon rank-sum tests were used for two group comparisons. Effect sizes for Kruskal-Wallis tests were computed as the $\eta$-squared $\left(\eta^{2}\right)$ based on the $\mathrm{H}$ statistic. For Wilcoxon rank-sum tests, the effect size $r$ was calculated as the $z$ statistic divided by the square root of the sample size.

\section{Results}

\section{Experimental design}

To determine the degree and directionality of communication between cells in modular and matrix regions of the LCIC, we performed whole-cell voltage-clamp recordings and stimulated presynaptic partners throughout the LCIC using laser photostimulation of caged glutamate (Fig. $1 A, B$ ). Module and matrix regions were visually distinguished under blue light illumination by their differential GAD67-GFP labeling in tissue slices from a transgenic mouse line. Modules are defined by their high densities of GAD67+ cells and terminals and appear as regions of high-intensity fluorescence embedded in the surrounding matrix (Fig. 1A). Both GAD67+ (presumed inhibitory) and GAD67(presumed excitatory) cells in both regions were recorded to measure inhibitory and excitatory inputs, respectively (Fig. 1A). For input mapping, a grid of stimulation sites was centered over the LCIC, and potential presynaptic partners were stimulated in a non-neighbor fashion (Fig. 1C). Responses were plotted spatially according to the location from which they were generated and converted into heat maps by computing the area under the curve of each response (Fig. 1C). Cells were voltage-clamped at +10 and $-60 \mathrm{mV}$ to measure inhibitory and excitatory currents, respectively (Fig. 1D). Excitation profiles were generated for each of the four cell types by recording spike output in cell-attached mode at various distances from the cell body (Fig. 1E). No significant differences were found in spike output between cell types, indicating that the specified laser parameters activate each population similarly (Fig. $1 F, G$ ). Two or three maps were averaged for each condition for each cell to account for variability between maps and spontaneous currents (Fig. 2). Excitatory mapping was repeated in low-calcium ACSF, and this "direct" input map was subtracted from the original excitatory map to isolate excitatory synaptic inputs (Fig. 2B-D).

\section{Input patterns for cells in matrix regions}

Inhibitory input maps were generated for a total of 26 GADand $30 \mathrm{GAD}+$ cells in matrix regions, and excitatory input maps were also obtained for 10 and 13 of these same cells, respectively. Heat maps were overlaid with an image of the GAD67-GFP labeling, and an ROI was drawn around the border of any modules present in the tissue (Fig. $3 A$, left). For matrix GAD- cells, inhibitory inputs predominately arose from stimulation sites in the matrix (Fig. $3 A$, middle left). Most of the excitatory input to these cells arose from direct activation of the recorded cell (Fig. $3 A$, middle right), and only sparse synaptic excitation was observed (Fig. $3 A$, left). Given the relative paucity of excitatory input at the population level compared with inhibitory input (Fig. 3D; $p=0.017$, Wilcoxon rank-sum test), additional example inhibitory input maps are shown without corresponding excitatory maps (Fig. 3B,C), demonstrating that the pattern of predominately matrix-derived input is conserved. This pattern was striking at the population level for both excitatory and inhibitory inputs, with a 10 -fold greater input charge arising from the matrix compared with the modules (Fig. $3 E$; inhibitory: $p=1.7 \mathrm{e}-06$, 
A

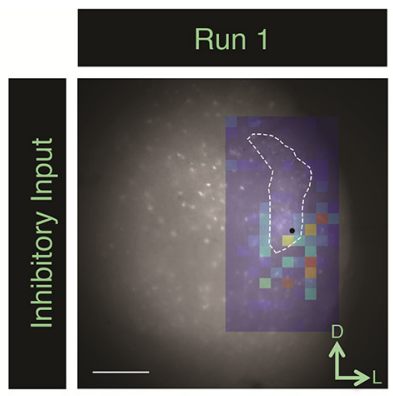

B

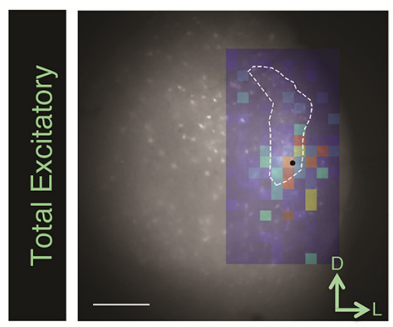

C

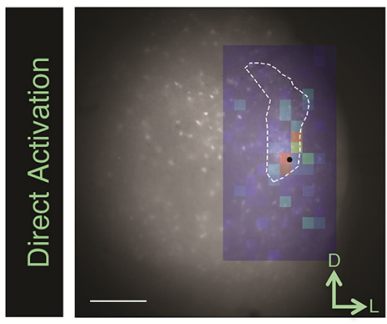

D
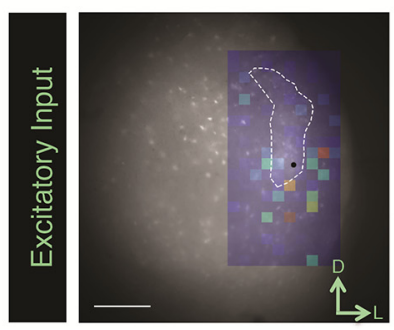
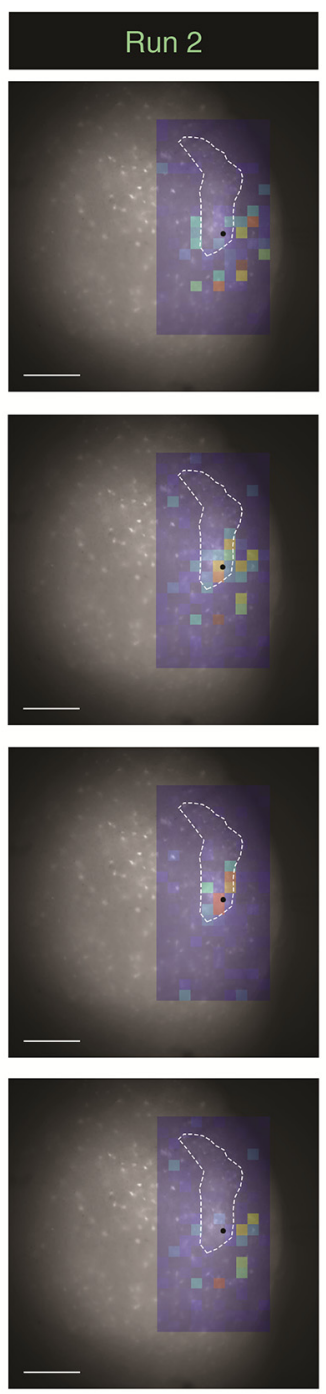
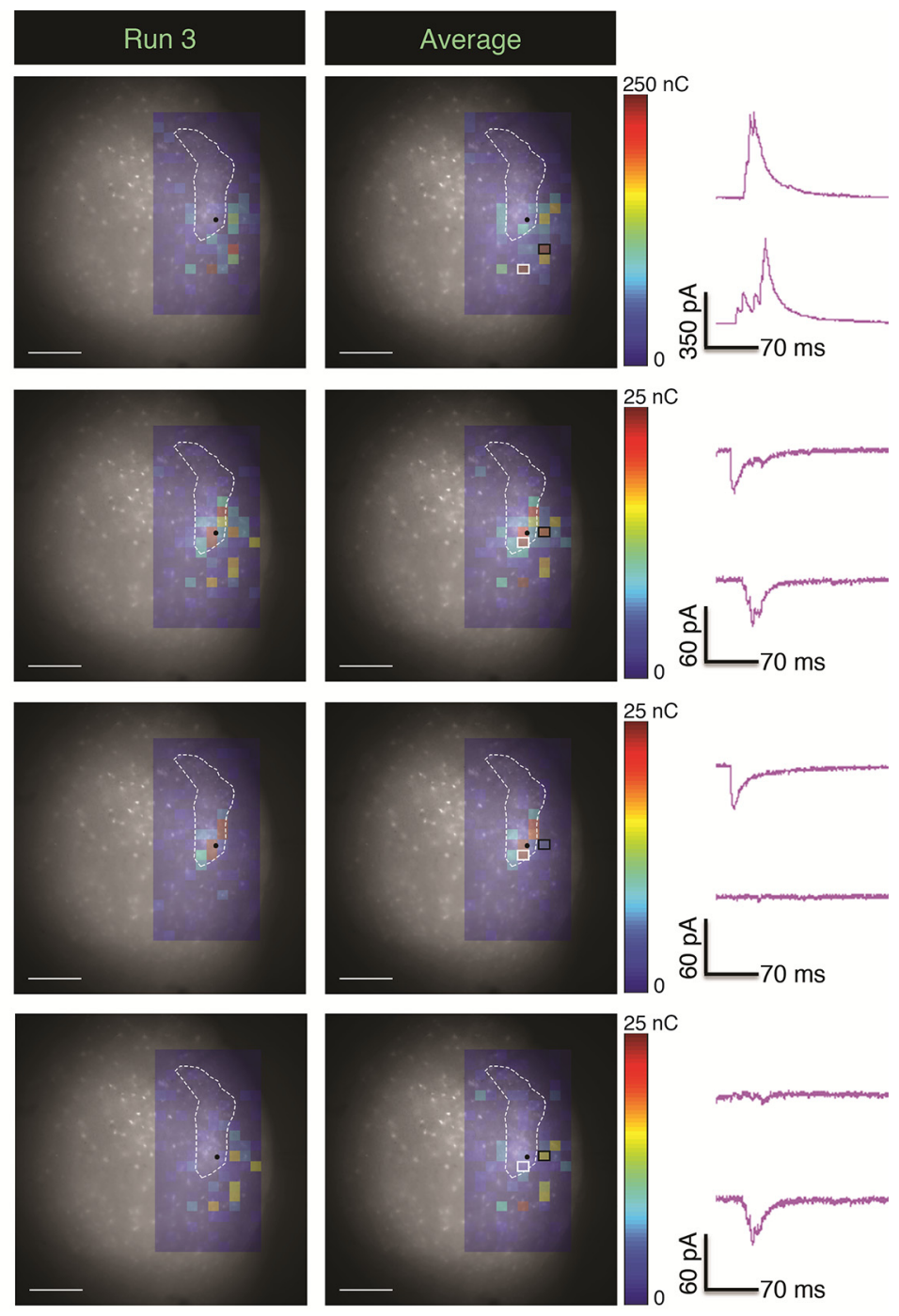

Figure 2. Examples of replicates of inhibitory and excitatory responses. $\boldsymbol{A}$, Inhibitory responses for three separate runs. The average maps (as shown in the final panel) were analyzed and used for quantification. Right, Example traces from two stimulation sites (top, white square; bottom, black square). $\boldsymbol{B}$, Total excitatory responses, including both direct activation and synaptic input to the recorded cell. $\boldsymbol{C}$, Excitatory responses in a low-calcium ACSF, which blocks synaptic inputs, giving rise to only direct activation of the recorded cell. The response in the bottom trace from $\boldsymbol{B}$ is no longer present, indicating that it was a synaptic input. $\boldsymbol{D}$, Maps of the excitatory synaptic inputs were generated by subtracting the direct input maps from the total excitatory maps. Scale bar, $400 \mu \mathrm{m}$.

$r=0.62$; excitatory: $p=0.00032, r=0.74$; Wilcoxon rank-sum tests).

A similar pattern of inhibitory input was seen for GAD + matrix cells, with virtually all of the inhibitory input arising from the matrix regions of the LCIC (Fig. $3 F-H$,J, left; $p=3.5 \mathrm{e}-08$, $r=0.71$; Wilcoxon rank-sum test). Unlike GAD- matrix cells, $\mathrm{GAD}+$ matrix cells received balanced levels of excitatory and inhibitory input overall (Fig. $3 F$, right, $I ; p=0.69$, Wilcoxon ranksum test). The spatial pattern of excitatory inputs, however, is consistent with those of GAD- matrix cells, in that an overwhelming majority of input arises from the matrix regions of the LCIC (Fig. $3 F$, right, $J$, right; $p=0.0023, r=0.58$, Wilcoxon ranksum test).

\section{Input patterns for cells in modules}

Inhibitory input maps were generated for $33 \mathrm{GAD}-$ and 34 $\mathrm{GAD}+$ cells in modules of the LCIC, and excitatory input maps were also obtained for 15 of these same cells for both cell types. Some GAD- cells in modules received predominately clustered inputs from within a module (Fig. $4 A$ ), whereas others received mixed input from both module and matrix regions (Fig. 4B,C). Overall, GAD- cells in modules received more inhibitory than excitatory input (Fig. 4D; $p=0.00088$, Wilcoxon rank-sum test). Spatial patterns of inhibitory and excitatory input were highly heterogeneous from cell to cell, with some cells receiving more input from modules, some receiving a balance of input from both domains, and some receiving more input from matrix regions (Fig. 4E). At the population level, this heterogeneity culminated in an overall similar level of input from both regions (Fig. $4 E ; p=0.10, r=0.21$ for inhibitory inputs and $p=0.37$, $r=0.17$ for excitatory inputs, Wilcoxon rank-sum tests). Input values from the matrix region remained consistent across cells, while the degree of input from the modules exhibited variability (Fig. 4E).

$\mathrm{GAD}+$ cells in modules showed a unique spatial pattern of input: most of the input to these cells arose from sites in the matrix, with very little input coming from the modules, where their cell bodies are located (Fig. $4 F-H$ ). Similar to GAD- cells in modules, GAD + cells in modules received predominately inhibitory input compared with excitatory input (Fig. 4I; $p=0.020$, 

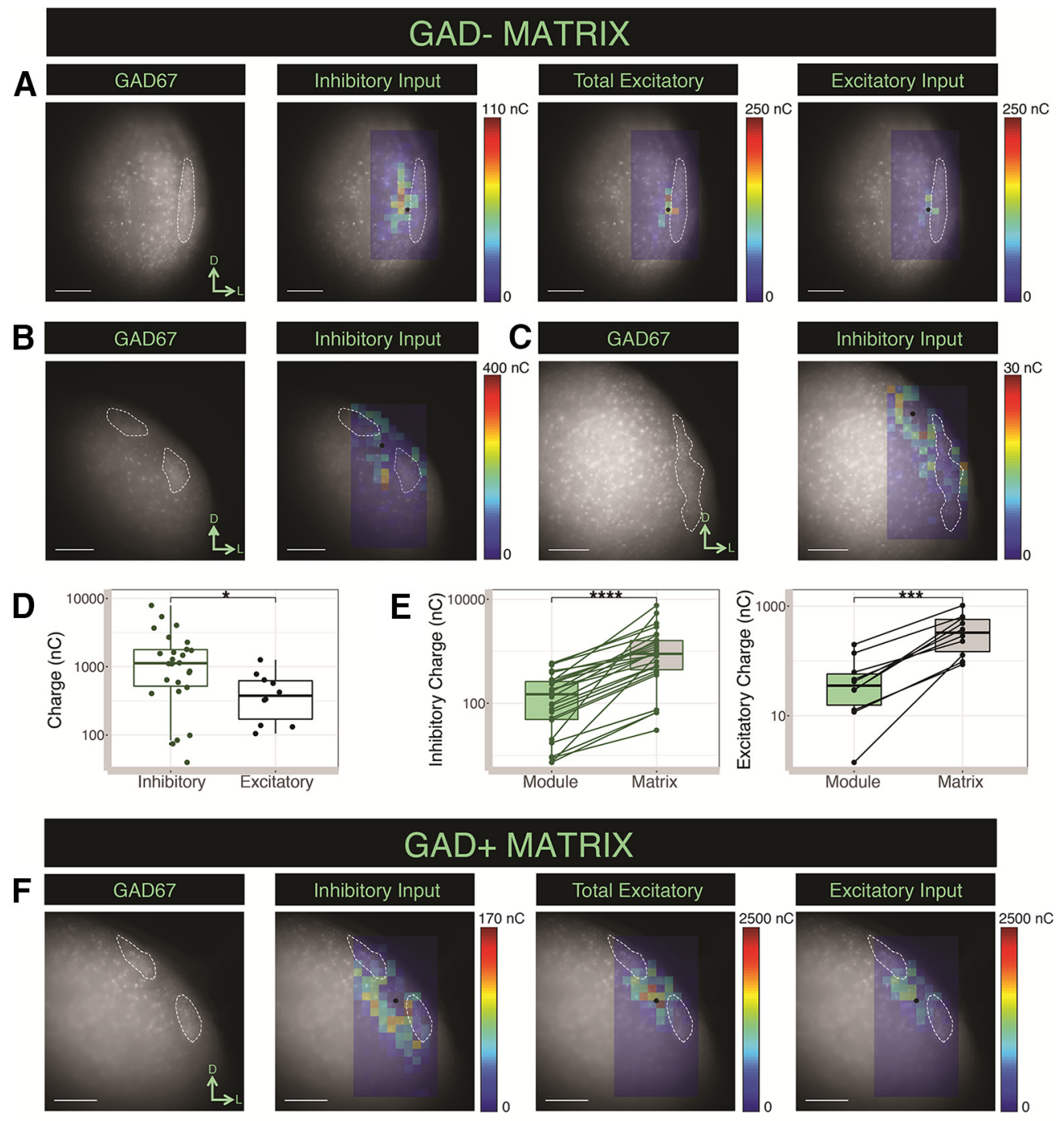

MATRIX
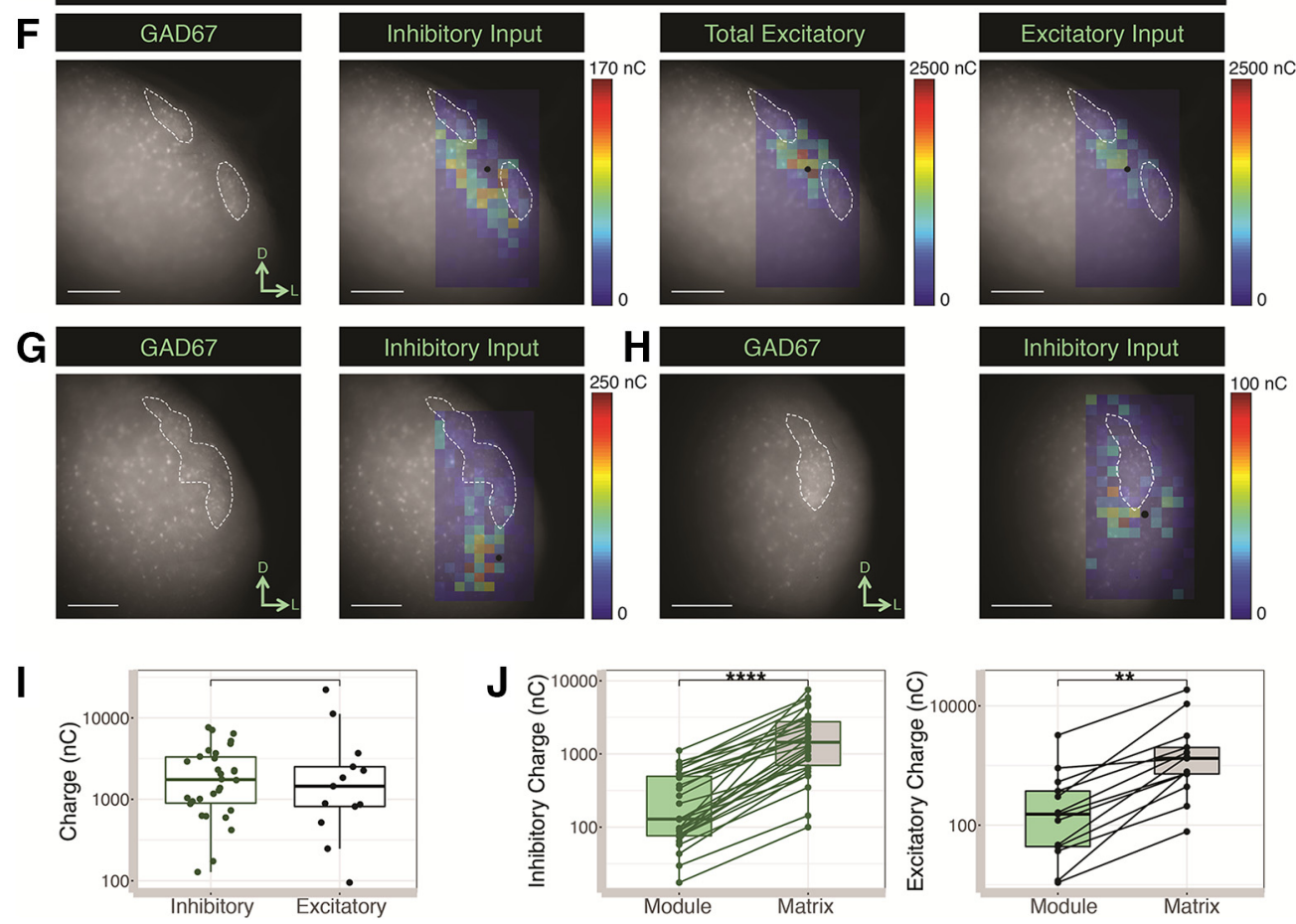

Figure 3. Input patterns for matrix cells. $A$, Example of inhibitory and excitatory inputs to a GAD- matrix cell in layer 3 of the LCIC. Black dot indicates the location of the cell body. White outlines indicate the borders of the modules. $\boldsymbol{B}$, Example of inhibitory inputs to a GAD- matrix cell positioned between two modules in layer 2 of the $L C I C$. $\boldsymbol{C}$, Example of inhibitory inputs to a GAD- matrix cell in layer 2 of the LCIC. D, The total inhibitory (mean $=1667.39 \mathrm{nC}$, median $=1125, \mathrm{SD}=1825.73, \mathrm{SEM}=358.06, \mathrm{Cl}= \pm 737.42, n=26$ cells) and excitatory (mean $=470.8$, median $=378.5, S D=358.75, S E M=113.45, C l= \pm 256.63, n=10$ cells) synaptic input to GAD- matrix cells. These cells receive significantly more inhibitory input than excitatory input. $E$, Inhibitory (matrix: mean $=1454.85$, median $=891, \mathrm{SD}=1742.15, \mathrm{SEM}=341.66, \mathrm{Cl}= \pm 703.66$; modules: mean $=191.34$, median $=150, \mathrm{SD}=182.07, \mathrm{SEM}=35.71, \mathrm{Cl}= \pm 73.54$ ) and excitatory (matrix: mean $=396.05$, median $=331, \mathrm{SD}=300.3, \mathrm{SEM}=94.96, \mathrm{Cl}= \pm 214.82$; modules: mean $=57.3$, median $=35.9, \mathrm{SD}=63.14, \mathrm{SEM}=19.97, \mathrm{Cl}= \pm 45.16)$ synaptic input to GAD- matrix cells parcellated by region of origin. GAD- matrix cells receive significantly more inhibitory and excitatory input from the matrix compared with the modular regions of the LCIC. $\boldsymbol{F}$, Example of inhibitory inputs to a GAD + matrix cell positioned between two modules in layer 2 of the LCIC. G, Example of inhibitory inputs to a GAD + matrix cell in layer 3 of the LCIC. $\boldsymbol{H}$, Example of inhibitory inputs to a GAD + matrix cell in layer 2 of the LCIC. I, The total inhibitory (mean: 2387.57, median: 1745, SD: 2072.93, SEM: 378.46, Cl: $\pm 774.04, n=30$ cells) and 
Wilcoxon rank-sum test). The spatial pattern of both excitatory and inhibitory inputs for GAD + cells in modules resembled those of matrix cells, with most of the input arising from the matrix, despite the difference in the compartmental location of the cell body (Fig. $4 J ; p=8.5 \mathrm{e}-06, r=0.51$ for inhibitory inputs and $p=0.0090$, $r=0.48$ for excitatory inputs, Wilcoxon rank-sum tests).

\section{Pharmacological controls}

Application of bath-applied GABAzine blocked inhibitory responses, suggesting that outward currents are mediated by $\mathrm{GABA}_{\mathrm{A}}$ receptors (Fig. $5 A$ ). We also repeated excitatory input mapping in the presence of GABAzine: (1) to determine whether inhibition in the LCIC was "masking" excitatory responses and (2) to confirm that our stimulation parameters did not elicit multisynaptic responses. In either instance, an increase in the overall map area would be expected in the presence of GABAzine. We observed that excitatory input maps remained largely unaltered (Fig. 5B,C). To confirm the validity of the low-calcium ACSF technique for segregating direct inputs from excitatory synaptic inputs, input mapping was repeated in TTX for a subset of cells (Fig. 5D,E). Similar input maps were generated using both techniques (Fig. $5 D, E$ ), as we have previously validated in other preparations (scale bar, $400 \mu \mathrm{m}$ ) (Slater et al., 2019).

\section{Balance of inhibitory and excitatory input from different regions of the $\mathrm{LCIC}$}

For each cell for which both inhibitory and excitatory input data were collected, an E:I index was computed to assess differences in the overall balance of excitation and inhibition at the population level. Each of the four cell types had a negative median E:I index, indicating that they are dominated by inhibition (Fig. 6A). No differences were found in the E:I index across groups at the population level (Fig. $6 A ; p=0.50$, Kruskal-Wallis rank-sum test).

To further assess differences in the balance of input from the module and matrix regions of the LCIC, a modularity index was calculated for each cell (the normalized difference in input from the compartment in which the cell body is located and the opposite region). Both cell types in the matrix exhibited high positive modularity indices for both inhibition and excitation, indicating that most of their input arises from matrix regions of the LCIC (Fig. 6B,C). GAD- cells in modules showed evidence of mixed input, with median excitatory and inhibitory modularity indices close to zero (Fig. 6B,C). Module GAD + cells had negative modularity indices (more pronounced for inhibition than excitation), indicating that most of their input arises from the matrix (Fig. $6 B, C)$. The modularity indices were significantly different between cell types, with the exception of the comparison between GAD - matrix and GAD + matrix cells for inhibitory input and between $\mathrm{GAD}-$ module and $\mathrm{GAD}+$ module cells for excitatory input (Fig. $6 B, C$; inhibitory: $p=2.2 \mathrm{e}-16, \eta^{2}=0.78$; excitatory: $p=$ $1.7 \mathrm{e}-08, \quad \eta^{2}=0.30$; Kruskal-Wallis rank-sum tests). These

$\leftarrow$

excitatory (mean: 3736.15 , median: 1450, SD: 6256.96, SEM: 1735.37, Cl: $\pm 3781.04, n=13$ cells) synaptic input to GAD + matrix cells. These cells receive balanced inhibitory and excitatory input. J, Inhibitory (matrix: mean $=2068.63$, median $=1450, S D=1892.51$, SEM $=$ $345.52, \mathrm{Cl}= \pm 706.67$; modules: mean $=300.03$, median $=129, \mathrm{SD}=287.07$, $\mathrm{SEM}=52.41$, $\mathrm{Cl}= \pm 107.19$ ) and excitatory (matrix: mean $=3231.16$, median $=1320, S D=5422.89$, $\mathrm{SEM}=1504.04, \mathrm{Cl}= \pm 3277.02$; modules: mean $=456.02$, median $=153, \mathrm{SD}=872.48$, $\mathrm{SEM}=241.98, \mathrm{Cl}= \pm 527.24)$ synaptic input to $\mathrm{GAD}+$ matrix cells parcellated by region of origin. $G A D+$ matrix cells receive significantly more inhibitory and excitatory input from the matrix compared with the modular regions of the LCIC. Scale bar, $400 \mu \mathrm{m}$. ${ }^{*} p<0.05$, ${ }^{* *} p$ $<0.01,{ }^{* * *} p<0.001,{ }^{* * *} p<0.0001$. findings indicate that there are distinct spatial patterns of input among different cell types in the LCIC.

\section{The local LCIC circuit}

The spatial patterns of input derived from the modularity indices for each cell type were used to construct a diagram of the local LCIC circuit (Fig. 6D). Both GAD- (putative excitatory) and $\mathrm{GAD}+$ (putative inhibitory) matrix cells receive excitatory and inhibitory input primarily from the matrix regions of the LCIC (i.e., GAD- and GAD + matrix cells predominately receive information from other GAD- and GAD + matrix cells) (Fig. $6 D$, area shaded in gray). GAD + cells in modules also receive most of their input from the matrix region (i.e., from GAD- and $\mathrm{GAD}+$ matrix cells), while GAD- cells in modules receive a mixture of input from both domains (i.e., from GAD- and $\mathrm{GAD}+$ cells in both matrix and modules) (Fig. $6 D$, area shaded in light green). Every cell type receives substantially more inhibitory than excitatory input (thick vs thin arrows in Fig. 6D; for comparisons between inhibitory and excitatory charge, see Fig. $6 A$ ). Together, these input patterns give rise to a predominately unidirectional flow of information from the matrix to the modular regions of the LCIC (Fig. 6D, gray arrow).

To determine whether individual cells' dendritic fields cross module borders, a subset of cells were filled with biocytin during recording to recover their neuronal morphology and local projection patterns. Both GAD- (Fig. 6E, left, white arrow) and $\mathrm{GAD}+$ (Fig. 6E, left green arrow) matrix cells had large and heavily branched dendritic arbors and axons that projected throughout the LCIC, sometimes extending into nearby modules (Fig. 6E, right, red arrows). These anatomic data support results from input mapping that show that matrix cells send information into modular regions of the LCIC. GAD + cells in modules (Fig. 6F, left, green arrow) also exhibited heavily branched dendritic arbors that frequently sprawled beyond the borders of their home modules (Fig. $6 F$, right, red arrow). This noncompartmentalized dendritic structure could serve as an anatomic substrate for the matrix-dominated input patterns revealed from photostimulation experiments. Unlike the other LCIC cell types, GADmodule cells (Fig. 6F, left, white arrow) typically had small dendritic trees that remained within the borders of their home modules (Fig. $6 F$, right, white arrow).

\section{Shared input to neurons in putative LCIC cell classes}

Since clear differences were observed in the inhibitory and excitatory input patterns for cells that differed in terms of location (module or matrix) and type $(\mathrm{GAD}+$ or $\mathrm{GAD}-$ ), we reasoned that each of these categories of cells comprises a distinct cell class. As such, we hypothesized that each cell class would share common local input, as measured during dual recordings (Fig. $7 A$ ). Therefore, dual recordings were made from 80 cells (40 pairs) that were either matched in terms of location and type (Fig. $7 B$ ), differed in only one parameter, or were unmatched in both parameters (Fig. 7C). The degree of input similarity was computed using two methods. Cross-correlations between the detailed time-courses at corresponding stimulation sites were computed, as described previously (Yoshimura and Callaway, 2005; Zarrinpar and Callaway, 2006). This method measures the similarity in the time-courses of synaptic inputs to two cells. In addition, the Pearson's correlation coefficient (Fisher $z$-transformed) using total inward current at corresponding sites for each pair of maps was also computed. This method emphasizes spatial similarity of inputs. These two metrics were compared across each group of pairs (Fig. $7 D, E)$. Using either method, we observed 

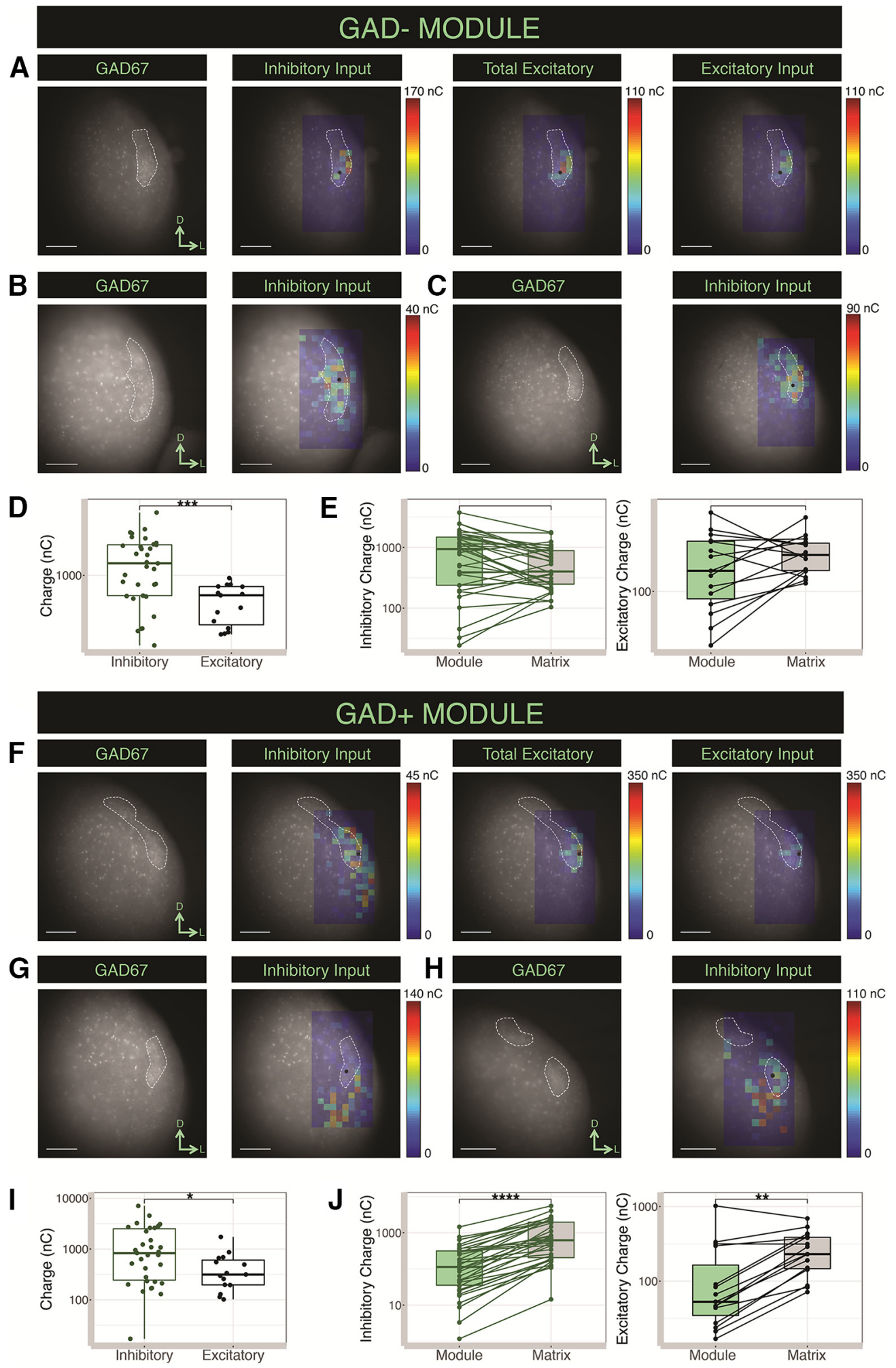

Figure 4. Input patterns for cells in module regions of the LCIC. $A$, Example of inhibitory and excitatory inputs to a GAD- cell in a module in the LCIC. Black dot indicates the location of the cell body. White outlines indicate the borders of the modules. $B$, Example of inhibitory inputs to a GAD- cell in a module in layer 2 of the LCIC. $C$, Example of inhibitory inputs to another GAD- cell in a module in layer 2 of the LCIC. D, The total inhibitory (mean: 1612.06 nC, median: 1390, SD: 1221.26, SEM: 212.59, Cl: $\pm 433.04, n=33$ cells) and excitatory (mean: 510.93, median: 580, SD: 251.08, SEM: 64.83 , Cl: $\pm 139.04, n=15$ cells) synaptic input to GAD- cells in modules. These cells receive significantly more inhibitory input than excitatory input. $E$, Inhibitory (matrix: mean $=596.03$, median $=400, S D=442.75, S E M=77.07, \mathrm{Cl}= \pm 156.99$; modules: mean $=1001.76$, median $=939, \mathrm{SD}=862.34, \mathrm{SEM}=150.11, \mathrm{Cl}= \pm 305.77$ ) and excitatory (matrix: mean $=265.4$, median $=245, S D=132.76, S E M=34.27, C l= \pm 73.52$; modules: mean $=231.69$, median $=166, S D=189.74, S E M=48.99, C l= \pm 105.07)$ synaptic input to GAD - cells in modules parcellated by region of origin. GAD - cells in modules receive equal input from the matrix and module regions of the LCIC for both inhibitory and excitatory inputs. $F$, Example of inhibitory inputs to a GAD + cell in a module in the LCIC. G, Example of inhibitory inputs to a GAD + cell in a module in layer 2 of the LCIC. $\boldsymbol{H}$, Example of inhibitory inputs to another GAD+ cell in a module in layer 2 of the LCIC. $I$, The total inhibitory (mean: 1398.94, median: 833, SD: 1540.33, SEM: 264.16, Cl: $\pm 537.44, n=34$ cells) and excitatory (mean: 464.13, median: 315 , SD: 423.31, SEM: 109.3, Cl: $\pm 234.42, n=15$ cells) synaptic input to GAD+ cells in modules. These cells receive more inhibitory than excitatory input. J, Inhibitory (matrix: mean $=1144.78$, 
that pairs that were more similar (in terms of cell type and location) had large values for both metrics, while cells that differed in one or both parameters had smaller values for both metrics (Fig. $7 D, E)$. Cross-correlation values were significantly different between different types of pairs $\left(p=0.015, \eta^{2}=0.21\right.$; KruskalWallis rank-sum test); specifically, pairs in which both the location and cell type were matched had significantly higher crosscorrelation values than pairs in which both of these parameters differed ( $p=0.0043$, post hoc Dunn's test with Holm correction). A similar pattern was seen for the correlation-coefficient analysis $\left(p=0.021, \eta^{2}=0.19\right.$, Kruskal-Wallis test; same vs difference: $p=0.0077$, post hoc Dunn's test with Holm correction). To determine whether the distance between the cells in a pair could account for these differences, we computed the regression coefficient between distance and cross-correlation values and found no relationship (Fig. $7 D ; R^{2}=-0.027, p=0.94$ ). Similarly, no relationship was found using distance as a predictor for correlation-coefficient values (Fig. $7 E ; R^{2}=0.059, p=0.073$ ) These data suggest that residence inside or outside of a module, as well as neurochemical identity, defines distinct cell classes in the LCIC and strongly determines local input patterns.

\section{Projections to other regions of the IC arise from the matrix}

Given the marked segregation of auditory and somatosensory inputs to the matrix and modular regions, respectively (Lesicko et al., 2016), and the modularity of LCIC microcircuit organization shown above, we hypothesized that outputs from the LCIC would also be organized along the basis of whether cells resided in a module/matrix or expressed GAD67. To test this idea, we examined four outputs of the LCIC: ipsilateral IC, contralateral IC (contraIC), superior colliculus (SC), and the medial division of the medial geniculate body (mMGB) and determined whether (1) they were located in the module or matrix region and (2) if they expressed GAD67 (Fig. 8A).

The subdivisions of the IC are heavily interconnected, and the LCIC projects to both the ipsilateral and contralateral DCIC and CNIC (Coleman and Clerici, 1987). To determine whether LCIC cells that project within the ipsilateral colliculus are also predominately distributed in either module or matrix regions, FG was injected into LCIC targets within the IC. The injection site was centered in the caudal half of the IC along the border between the DCIC and the CNIC (Fig. 8A, left). UV illumination revealed several retrogradely labeled cells in the LCIC (Fig. $8 B$, middle left). Overlay images showed that cells that project to the ipsilateral IC are found almost exclusively (97\%) in matrix regions of the LCIC (Figs. 8B,C, 9E). However, a substantial percentage (33\%) of back-labeled cells were found to be GFP-positive, indicating that this pathway is partially GABAergic (Fig. 9E).

To examine the projection pattern to the contraIC, an injection of FG was placed in the ventromedial and mid-rostrocaudal portion of this structure (Fig. $8 A$, middle left). Back-labeled cells were found throughout all subdivisions of the IC (Fig. 8D) and were most concentrated along the same rostrocaudal plane as the injection site (Fig. $8 E$, right). Overlay images revealed that the

$\leftarrow$

median $=624, \mathrm{SD}=1270.96, \mathrm{SEM}=217.97, \mathrm{Cl}= \pm 443.46$; modules: mean $=231.31$, median $=113.9, \mathrm{SD}=297.02, \mathrm{SEM}=50.94, \mathrm{Cl}= \pm 103.64$ ) and excitatory (matrix: mean $=$ 281.34, median $=230, \mathrm{SD}=179.2, \mathrm{SEM}=46.27, \mathrm{Cl}= \pm 99.24$; modules: mean $=165.92$, median $=52.9, \mathrm{SD}=261.73, \mathrm{SEM}=67.58, \mathrm{Cl}= \pm 144.94$ ) synaptic input to $\mathrm{GAD}+$ cells in modules parcellated by region of origin. $\mathrm{GAD}+$ cells in modules receive significantly more inhibitory and excitatory input from the matrix compared with the module regions of the LCIC. Scale bar, $400 \mu \mathrm{m} .{ }^{*} p<0.05,{ }^{* *} p<0.01,{ }^{* * *} p<0.001,{ }^{* * * *} p<0.0001$. pattern of outputs to the contraIC mimics the pattern to the ipsilateral IC; the vast majority (98\%) of back-labeled cells are found in matrix regions of the LCIC (Figs. $8 D, E, 9 E$ ). However, a smaller proportion of back-labeled cells were found to be GFPpositive (4\%), indicating that this pathway is predominately nonGABAergic (Fig. 9E).

\section{Inputs to the SC also come from the matrix zone}

To examine the distribution pattern of outputs to the SC, FG was injected at a mid-rostrocaudal level of the SC, in both deep and superficial layers (Fig. 8A, middle right). Overlay images of the FG and GAD67-GFP labeling revealed that (1) cells projecting to the SC were almost exclusively found in the matrix regions of the LCIC and (2) the vast majority of retrogradely labeled cells were non-GABAergic (Fig. 9A,B). These observations were confirmed with quantification; cell counts revealed that $96 \%$ of the retrogradely labeled cells in the LCIC were found in matrix regions, and that $96 \%$ were also non-GABAergic (Fig. 9E). Although cells projecting to the SC were found throughout the rostrocaudal extent of the LCIC, they were heavily concentrated in the rostralmost regions of the LCIC (Fig. 9B).

\section{Cells projecting to the $\mathrm{mMGB}$ are found in modules}

All subdivisions of the IC project heavily to the MGB, and the main thalamic target of the LCIC is the mMGB (Calford and Aitkin, 1983). A small deposit of FG was made in this region to back-label colliculo-thalamic cells and determine whether their distribution in the LCIC is patterned (Fig. 8A, right). As shown, the injection site appeared largely restricted to the $\mathrm{mMGB}$, with potential spillover into the surrounding paralaminar nuclei (i.e., the suprageniculate nucleus and the posterior intralaminar nucleus) (Goldowitz, 2010). In contrast to cells projecting to the SC and IC, cells projecting to the mMGB were found to form clusters that were largely found within the modules (Fig. 9C,D). Back-labeled cells were found throughout the rostrocaudal extent of the LCIC (Fig. 9D). Cell counts revealed that $86 \%$ of these cells were found in modules of the LCIC, while the remaining cells were found in the matrix. Interestingly, of the 404 FG-labeled cells that were identified in the LCIC, none was found to be double-labeled with GFP, indicating that this pathway is strictly nonGABAergic (Fig. 9E).

\section{Discussion}

In the present study, we used a combination of single and paired whole-cell voltage-clamp recordings, laser photostimulation, and tract-tracing to measure functional patterns of integration and segregation in a brain structure containing strong anatomic modularity, the LCIC.

Our photostimulation studies suggest that local input patterns for LCIC cells are strongly dependent on their neurochemical identity (GAD+ or GAD-) and location (module or matrix), with distinct yet highly consistent input phenotypes found for each cell type. Both GAD- and GAD + matrix cells receive input mainly from the matrix but relay information to cells in both the module and matrix compartments of the LCIC. Although cells in modules receive input from both domains of the LCIC, they predominately relay it to other cells within the modules (Figs. $6 D$, 10 ). This circuitry gives rise to a directional flow of information predominately from the matrix to module regions of the LCIC. One advantage of such an arrangement could be to allow for independent modulation of auditory and somatosensory inputs while retaining local circuit mechanisms that allow for multimodal integration (see below). These data suggest that anatomic 

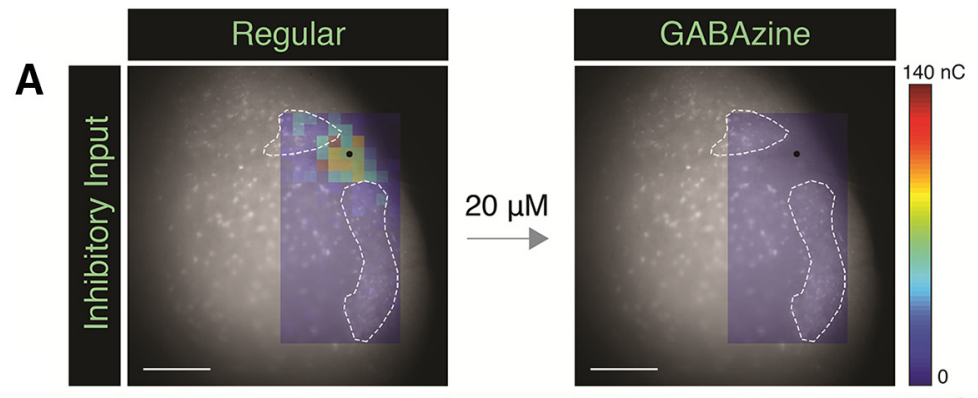

B
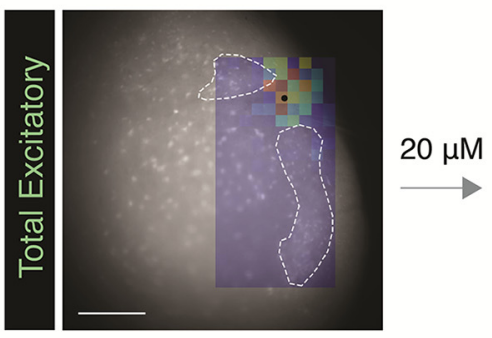

C
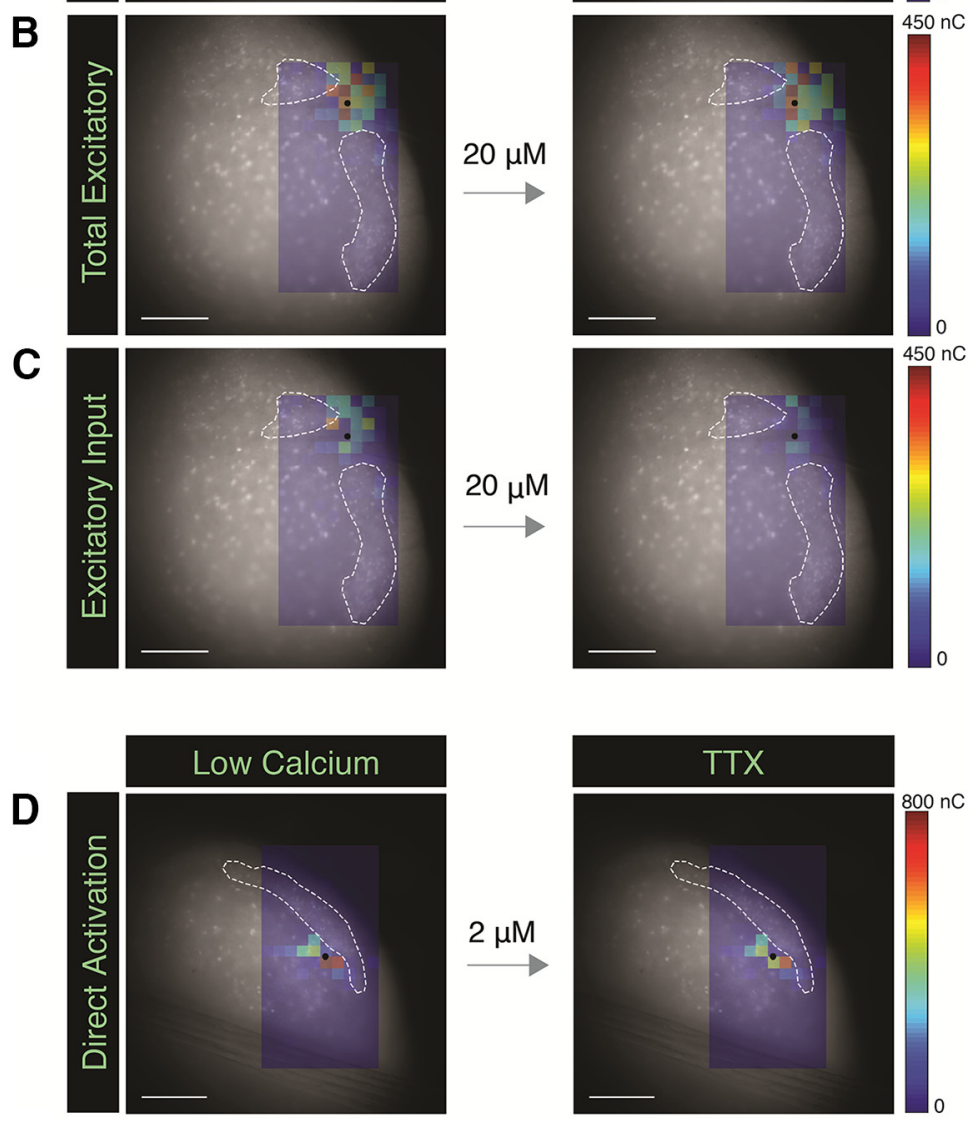

$\mathbf{E}$
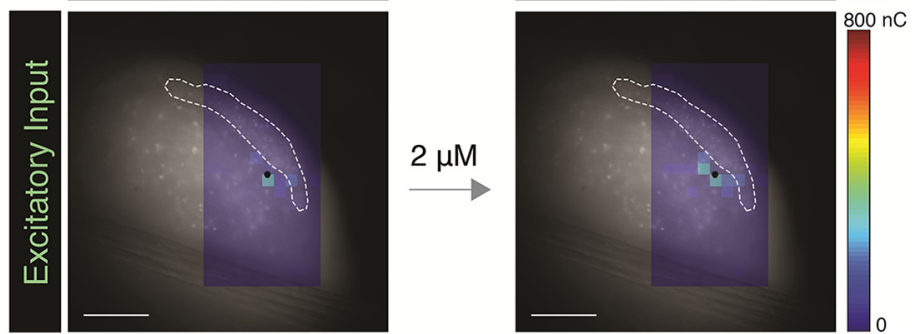

Figure 5. Pharmacological controls with GABAzine and TTX. $\boldsymbol{A}$, Example map showing the effect of $20 \mu \mathrm{m}$ GABAzine on inhibitory inputs. Right, Inhibitory inputs are abolished. $\boldsymbol{B}$, Effect of GABAzine on the total excitatory (including direct activation) input to the same cell shown in $\boldsymbol{A}$. $\boldsymbol{C}$, Effect of GABAzine on the excitatory synaptic input of the same cell shown in $\boldsymbol{A}$ and $\boldsymbol{B}$. Scale bar, $400 \mu \mathrm{m}$. D, Map of direct activation generated in low-calcium ACSF (left) and TTX (right). Note the similarity in the distribution of input sites. $\boldsymbol{E}$, Maps of excitatory synaptic input for each condition from the same cell shown in $\boldsymbol{A}$. Scale bar, $400 \mu \mathrm{m}$.

modules in the LCIC serve as guideposts to segregate the massive converging input onto this structure, as further described below.

\section{Outputs of the LCIC are associated with distinct extrinsic inputs}

We observed that the widely divergent outputs of the LCIC to the SC, mMGB, and ipsilateral and contralateral IC were nearly entirely determined by whether the cells of origin were found in the matrix or modules. These segregated streams of outputs have previously been shown to be targeted by distinct inputs. LCIC modules receive input from somatosensory structures, such as the dorsal column nuclei and the primary somatosensory cortex (Lesicko et al., 2016) (Fig. 10, purple arrows). Matrix areas of the LCIC, on the other hand, are targeted by auditory structures, such as the $\mathrm{AC}$ and the CNIC (Lesicko et al., 2016) (Fig. 10, teal arrows). Although these two subregions of the LCIC are segregated on the basis of their neurochemistry and connectivity, they do not form wholly separate processing streams; cells in modular regions of the LCIC receive input from the matrix. These connections could serve to route auditory information into the somatosensory-recipient modules, thereby forming multisensory processing zones. The local connections in the LCIC appear largely unidirectional, in that the matrix regions receive very little input from the modules (Fig. 6B,C). This combination of segregated inputs and outputs and highly specific local integration could therefore maximize the computational possibilities among parallel streams of information. For example, matrix regions of the LCIC could perform computations related to auditory processing and route it to midbrain targets, including the SC and other regions of the IC, while the modules may integrate somatosensory and auditory information and route it to the mMGB. Although we have demonstrated a clear connection between the distribution of cells giving rise to these particular output pathways and the underlying neurochemical modularity present in the LC, it is worth noting that there are a number of additional targets of the LC whose subcompartment of origin remains unknown, including outputs to additional subdivisions of the auditory thalamus and descending projections to the auditory brainstem (Caicedo and Herbert, 1993; Linke, 1999).

Similarities to patch/matrix compartments of the striatum While the function of the neurochemical and connectional modularity found in the LCIC remains unknown, studies in other structures with a similar organization can help shed light on the potential advantage of such an arrangement. Modularity is also present in the striatum, with inputs and outputs being segregated 
A

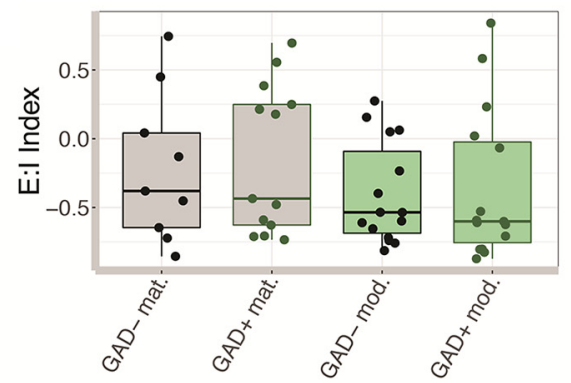

C

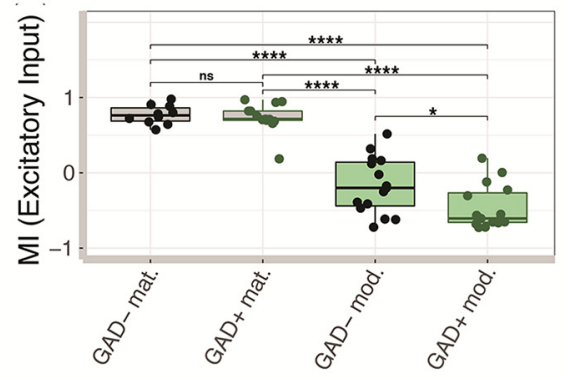

B

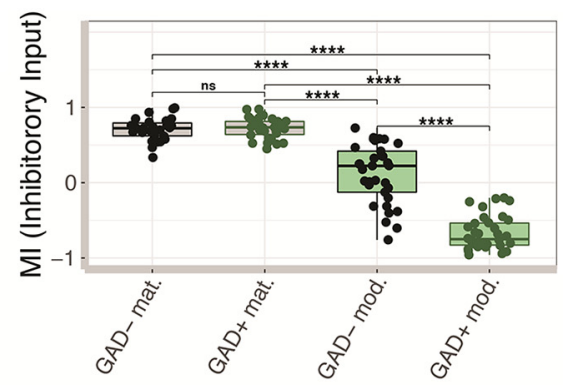

D

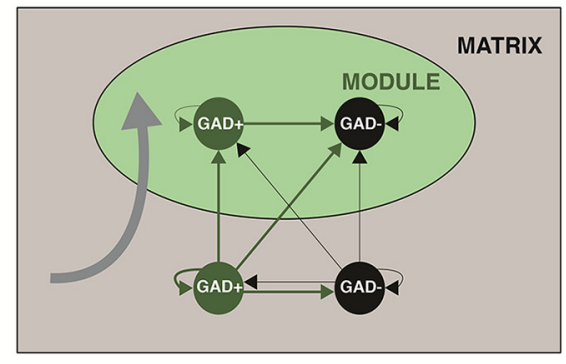

$\mathbf{E}$

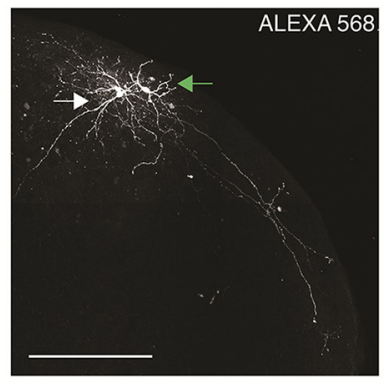

$\mathbf{F}$

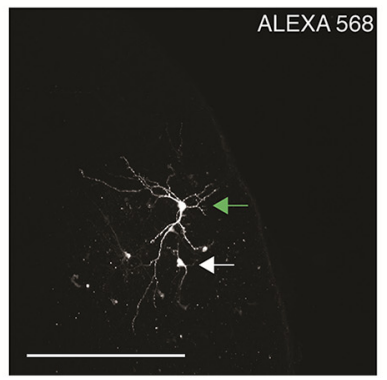

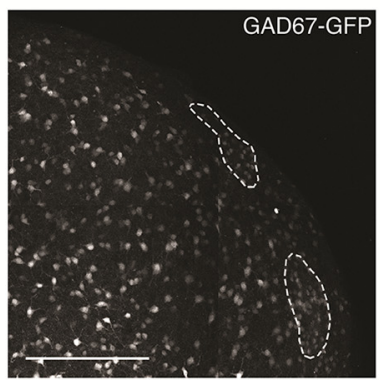
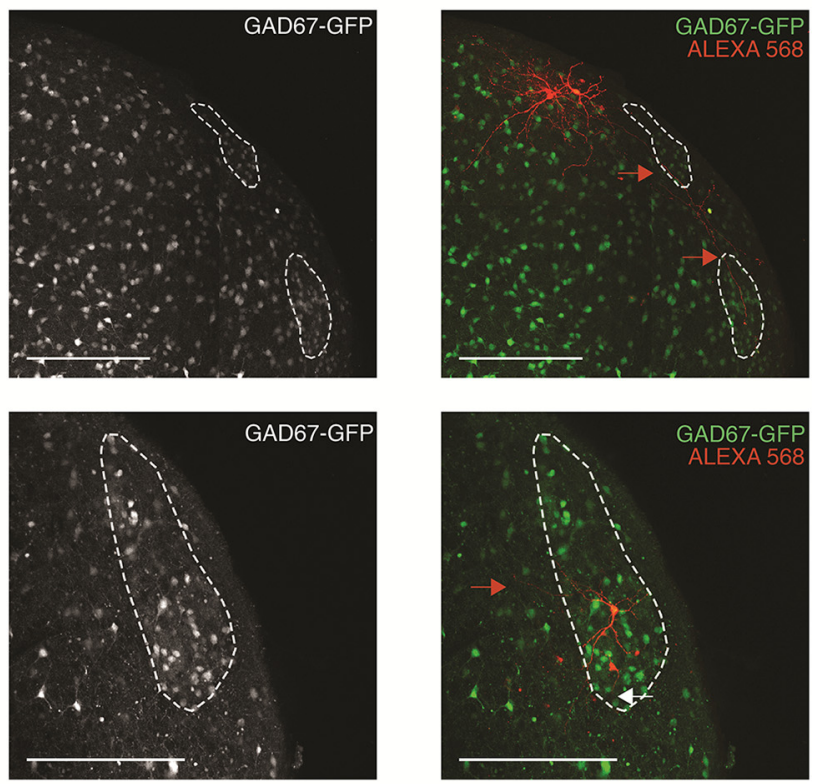

Figure 6. Cell type-specific input patterns yield a largely unidirectional flow of information in the LCIC microcircuitry. $A$, E:I indices each of the four cell types $(G A D-$ matrix: mean $=$ -0.22 , median $=-0.38, \mathrm{SD}=0.54, \mathrm{SEM}=0.18, \mathrm{Cl}= \pm 0.42, n=9$ cells; $\mathrm{GAD}+$ matrix: mean $=-0.15$, median $=-0.44, \mathrm{SD}=0.54, \mathrm{SEM}=0.15, \mathrm{Cl}= \pm 0.33, n=13$ cells; $\mathrm{GAD}-$ module:mean $=-0.4$, median $=-0.54, \mathrm{SD}=0.37, \mathrm{SEM}=0.1, \mathrm{Cl}= \pm 0.2, n=15$ cells; $\mathrm{GAD}+$ module: mean $=-0.35$, median $=-0.6, \mathrm{SD}=0.55, \mathrm{SEM}=0.14, \mathrm{Cl}= \pm 0.3, n=15$ cells). The mean and median E:l index is negative for each cell type, indicating that the balance of charge is skewed toward inhibition. $\boldsymbol{B}$, Modularity indices (MI) for the inhibitory inputs to each of the four cell types of interest (GAD- matrix: mean $=0.71$, median $=0.72, S D=0.15, S E M=0.03, C l= \pm 0.06, n=26$ cells; $G A D+$ matrix: mean $=0.72$, median $=0.74, S D=0.14, S E M=0.03$, $\mathrm{Cl}= \pm 0.05, n=30$ cells; GAD - module: mean $=0.12$, median $=0.22, \mathrm{SD}=0.39, \mathrm{SEM}=0.07, \mathrm{Cl}= \pm 0.14, n=33$ cells; GAD + module: mean $=-0.67$, median $=-0.75, \mathrm{SD}=0.22$, $\mathrm{SEM}=0.04, \mathrm{Cl}= \pm 0.08, n=34$ cells). C, Modularity indices for the excitatory inputs to each of the four cell types of interest (GAD - matrix: mean $=0.77$, median $=0.76, \mathrm{SD}=0.13$, $\mathrm{SEM}=0.04, \mathrm{Cl}= \pm 0.09, n=10$ cells; $\mathrm{GAD}+$ matrix: mean $=0.74$, median $=0.71, \mathrm{SD}=0.2, \mathrm{SEM}=0.05, \mathrm{Cl}= \pm 0.12, n=13$ cells; GAD - module: mean $=-0.17$, median $=-0.2$, $\mathrm{SD}=0.37, \mathrm{SEM}=0.1, \mathrm{Cl}= \pm 0.21, n=15$ cells; GAD + module: mean $=-0.46$, median $=-0.61, \mathrm{SD}=0.29, \mathrm{SEM}=0.08, \mathrm{Cl}= \pm 0.16, n=15$ cells). $\boldsymbol{D}$, Cell type-specific input patterns give rise to a largely unidirectional flow of information from matrix to modular regions of the LCIC. $E$, Neuronal morphology for a GAD - (white arrow left) and GAD + (green arrow left) matrix cell. Note the axons terminating in nearby modules (red arrow right). $\boldsymbol{F}$, Neuronal morphology for a GAD - (white arrow left) and GAD+ (green arrow left) cell located in a module. Note the differences in dendritic arborization, with the GAD + cell's dendrites extending beyond the borders of the modules (red arrow right) and GAD - cell's dendrites confined to the modules (white arrow right). Scale bar, $250 \mu \mathrm{m} .{ }^{*} p<0.05,{ }^{* *} p<0.01,{ }^{* * * *} p<0.0001$, ns, not significant.

according to whether they are found in the acetylcholinerich "matrix" areas or the opiate receptor-dense "patch" areas (Graybiel and Ragsdale, 1978; Gerfen, 1984; Kincaid and Wilson, 1996). Studies that have investigated whether the two domains are fully segregated have found that the dendrites of retrogradely filled cells in both compartments are confined to the region containing their cell bodies (Gerfen, 1985). While this finding suggests that the two compartments may form segregated processing streams, additional experiments have shown that intrinsic somatostatin-positive neurons form a bridge between the patch and matrix regions; the cell bodies of these interneurons are found in both regions, but their axons 
A

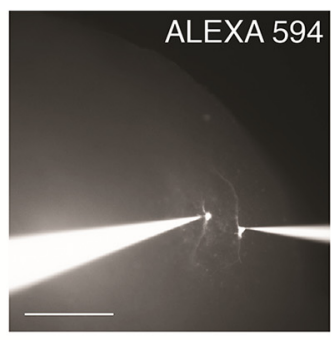

B

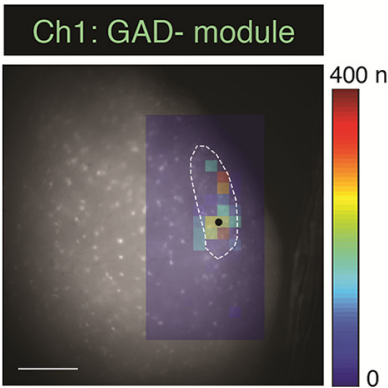

C
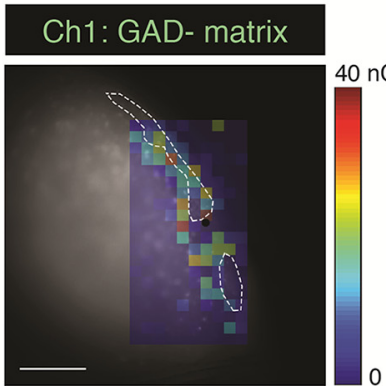

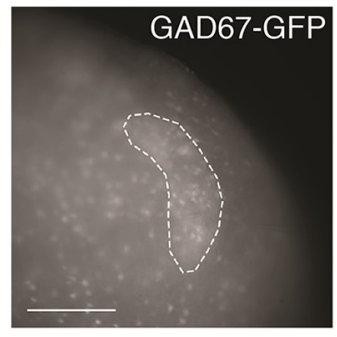

Ch2: GAD- module

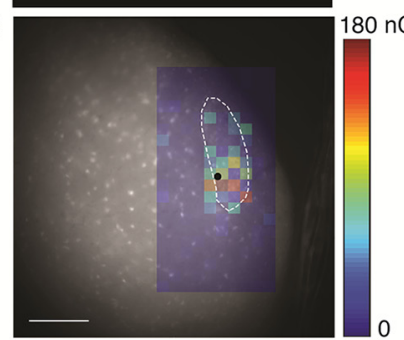

Ch2: GAD+ module

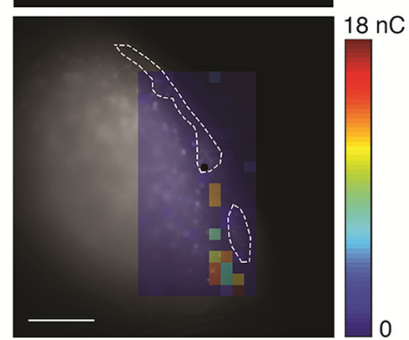

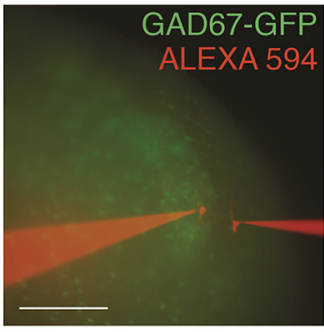

Cross-correlation

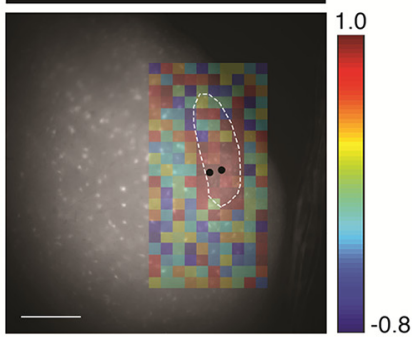

Cross-correlation

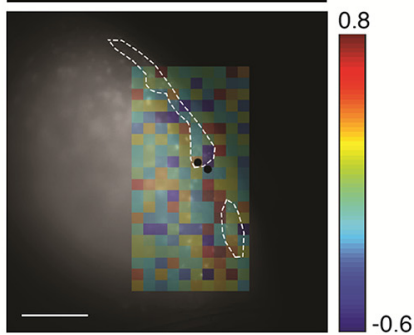

D

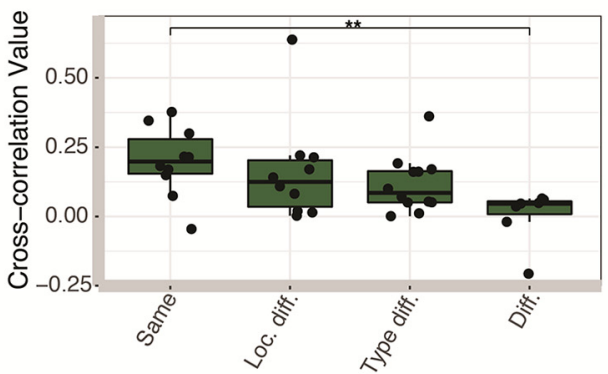

E

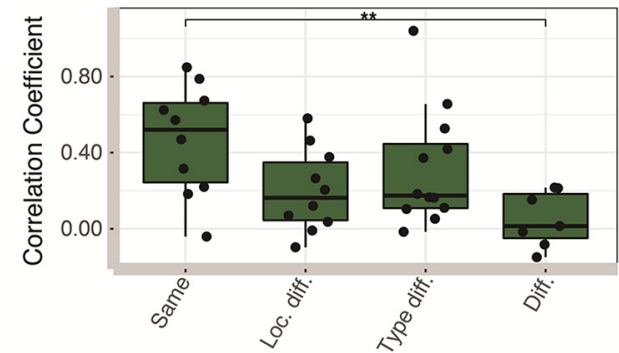

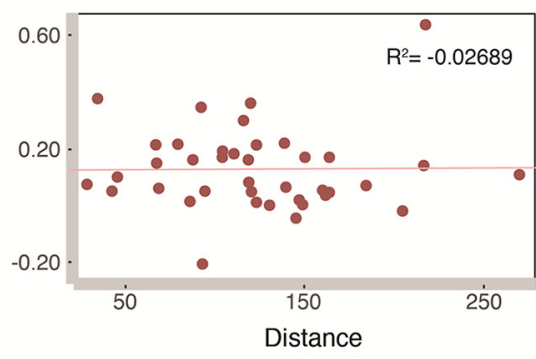

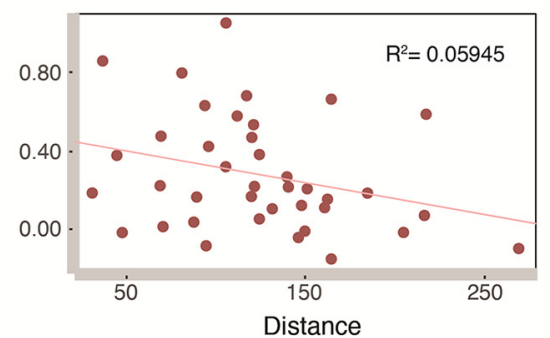

Figure 7. Dual recordings. $A$, Example of a pair of simultaneously recorded cells. $B, A$ pair of cells that is matched in terms of location and type. Note the prominent pattern of clustered positive values in the map of cross-correlations. $C$, A pair of cells that differs in both location and type. Note the absence of a pattern in the cross-correlation map. $\boldsymbol{D}$, Left, Average cross-correlation values for each category of pairs (both same: mean $=0.2$, median $=0.2, S D=0.13, S E M=0.04, C I= \pm 0.09, n=10$ pairs; location different: mean $=0.16$, median $=0.12, S D=0.19$, $\mathrm{SEM}=0.06 ; \mathrm{Cl}= \pm 0.13, n=10$ pairs; type different: mean $=0.12$, median $=0.09, \mathrm{SD}=0.1, \mathrm{SEM}=0.03, \mathrm{Cl}= \pm 0.06, n=12$ pairs; both different: mean $=0.004$, median $=0.05, \mathrm{SD}=0.1$, $\mathrm{SEM}=0.04 ; \mathrm{Cl}= \pm 0.09, n=7$ pairs). Right, Distance versus cross-correlation value between simultaneously recorded cells. $\boldsymbol{E}$, Left, Correlation-coefficient values for each category of pairs (both same: mean $=0.47$, median $=0.52, \mathrm{SD}=0.29, \mathrm{SEM}=0.09, \mathrm{Cl}= \pm 0.21, n=10$ pairs; location different: mean $=0.2$, median $=0.16, \mathrm{SD}=0.22, \mathrm{SEM}=0.07 ; \mathrm{Cl}= \pm 0.16, n=10$ pairs; type different: mean $=0.31$, median $=0.17, \mathrm{SD}=0.31, \mathrm{SEM}=0.09, \mathrm{Cl}= \pm 0.19, n=12$ pairs; both different: mean $=0.05$, median $=0.01, \mathrm{SD}=0.15, \mathrm{SEM}=0.06, \mathrm{Cl}= \pm 0.13, n=7$ pairs). Scale bar, $400 \mu \mathrm{m}$. Right, Distance versus correlation coefficient value between simultaneously recorded cells. ${ }^{* *} p<0.01$. 

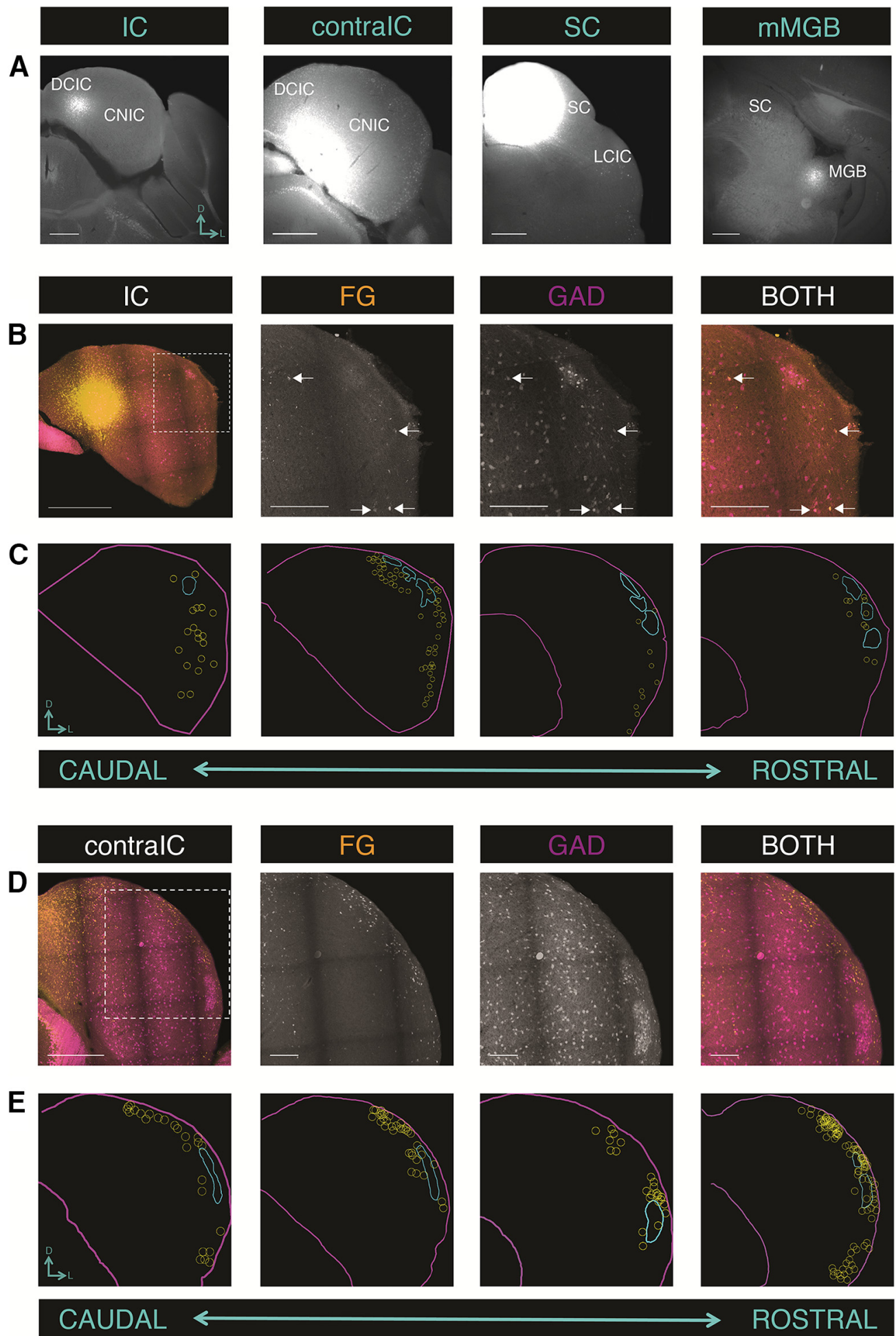

Figure 8. Cells that project to the ipsilateral IC and contralC are found in matrix regions of the LCIC. $A$, FG injection sites. B, FG labeling in the LCIC after an ipsilateral IC injection in a GAD67-GFP mouse. White arrows indicate examples of double-labeled GAD + and FG + cells. C, Rostrocaudal distribution of cells in the LCIC that project to other regions of the ipsilateral IC. $D$, FG labeling in the LCIC after an injection in the contralC of a GAD67-GFP mouse. $\boldsymbol{E}$, Rostrocaudal distribution of cells in the LCIC that project to the contralC. Scale bars: $\boldsymbol{A}, \boldsymbol{B}, 1000 \mu \mathrm{m}$; inset, $250 \mu \mathrm{m} ; C, D, 500 \mu \mathrm{m}$; inset, $250 \mu \mathrm{m}$.

selectively innervate the matrix compartment (Gerfen, 1985). Single somatostatin-immunoreactive cells in the patch compartment send axons to the surrounding matrix, suggesting that these cells provide a unidirectional projection from the patch to the matrix. Interestingly, this organization bears resemblance to the largely directional flow of information from the matrix to module regions demonstrated in the present study (Fig. 6). 

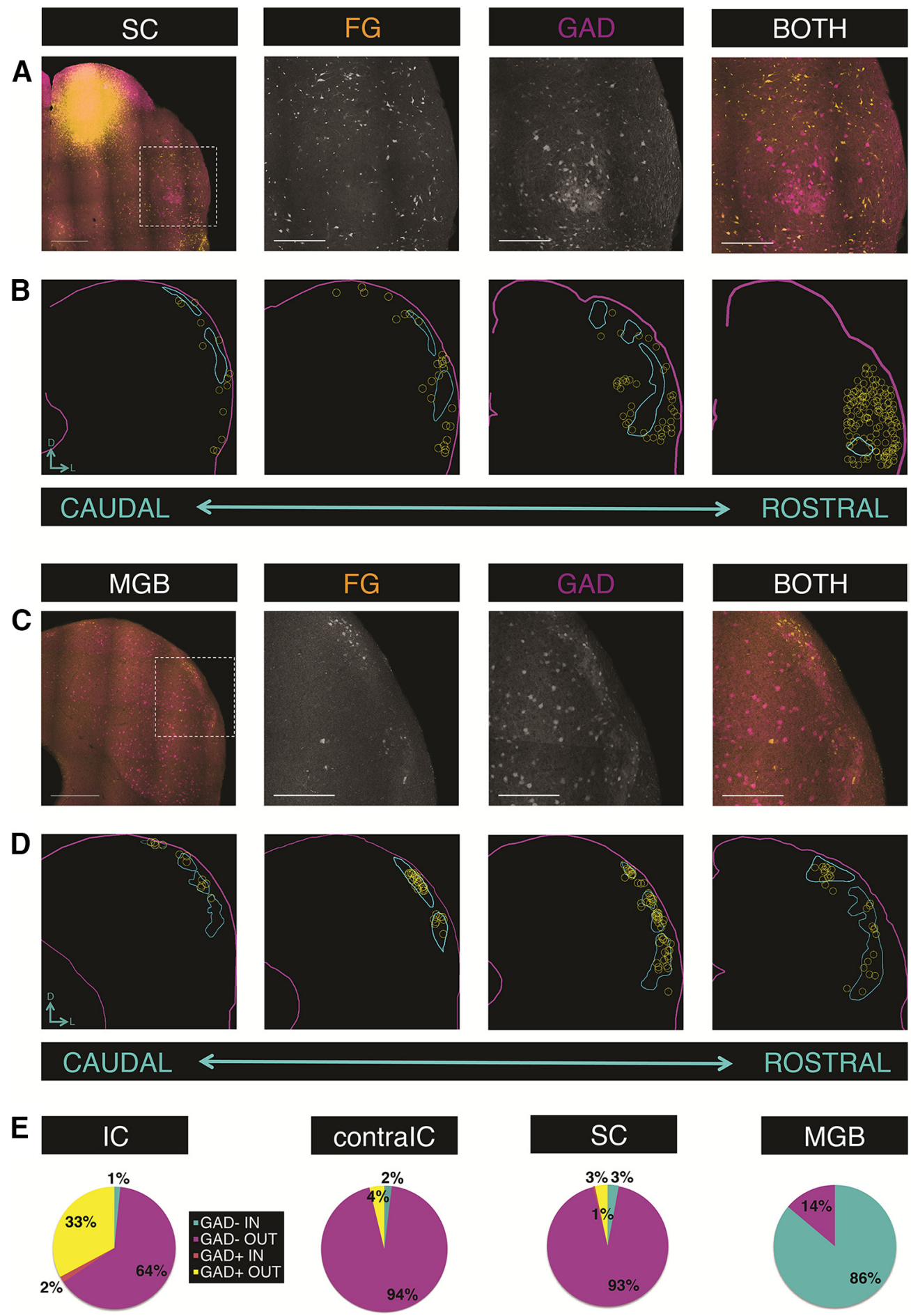

Figure 9. Distribution of cells that project to the SC and mMGB. $A$, FG labeling in the LCIC after an SC injection in a GAD67-GFP mouse. B, Rostrocaudal distribution of cells in the LCIC that project to the SC. C, FG labeling in the LCIC after an mMGB injection in a GAD67-GFP mouse. D, Rostrocaudal distribution of cells in the LCIC that project to the mMGB. $\boldsymbol{E}$, Percentage of GABAergic and non-GABAergic cells from each LCIC subregion projecting to various targets. Scale bars, $500 \mu \mathrm{m}$; inset, $250 \mu \mathrm{m}$.

\section{Implications for multisensory processing}

The results of the present study suggest a mechanism by which multisensory convergence could occur within the LCIC. Further studies will be required to determine whether single cells within the modules receive convergent input from both of these sources. It is presently unknown whether as a population the dendrites of cells within module and matrix zones are confined to the region containing their soma, as is the case with other modular structures, such as the striatum and the pons (Gerfen, 1985; Schwarz and Thier, 1995). If not, multisensory integration could also arise from direct input to a cell whose dendrites cross the module/matrix boundary. The advantage of having multisensory convergence arise from a local circuit mechanism rather than direct convergence of extrinsic inputs is presently unclear but may permit independent modulation of each input before their convergence. 


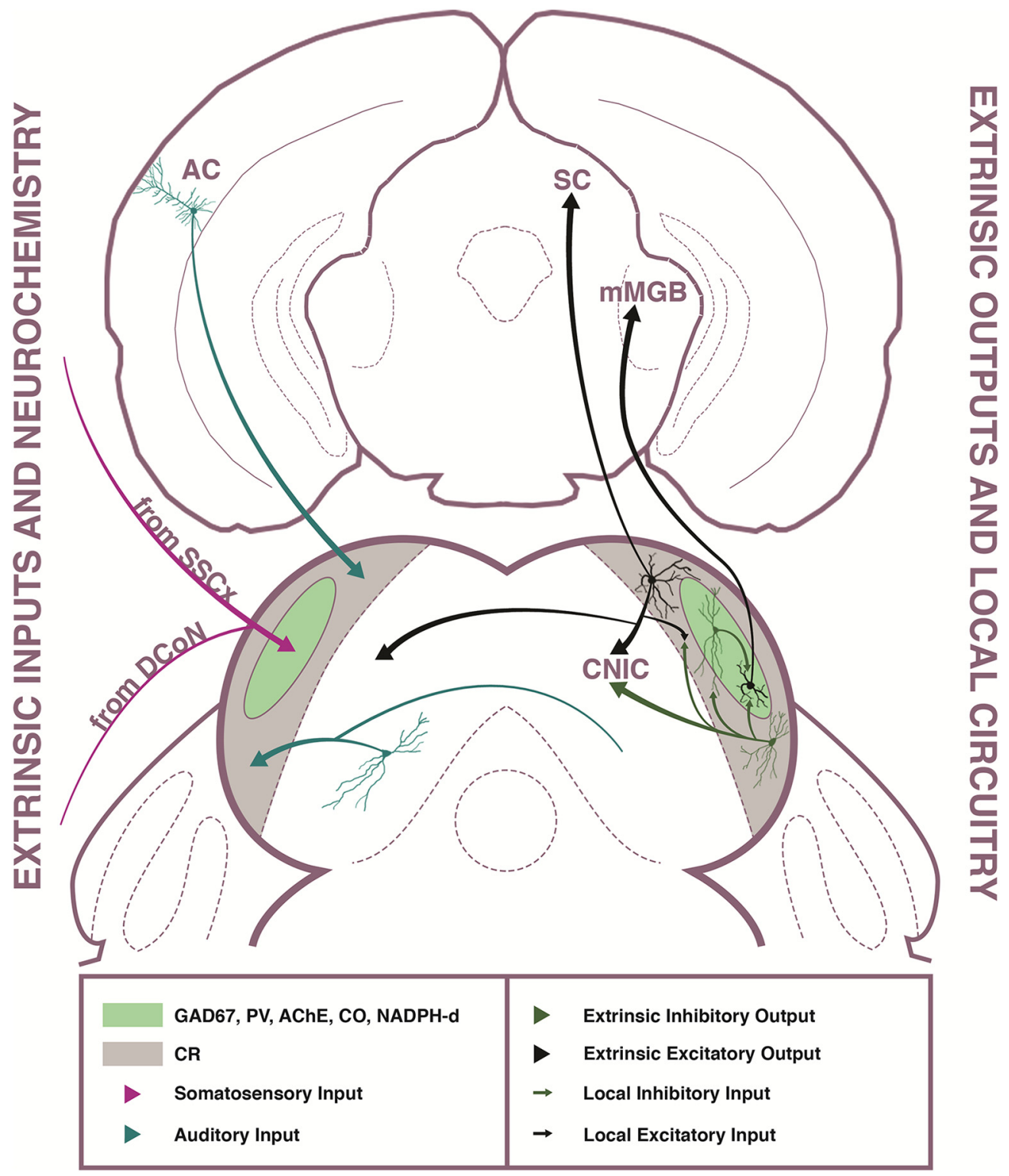

Figure 10. Summary diagram of modularity in the LCIC neurochemistry, extrinsic inputs and outputs, and local circuitry. Left, Somatosensory inputs (purple arrows) arising from the dorsal column nuclei and primary somatosensory cortex target modular regions of the LCIC, whereas auditory inputs (teal arrows) from the ipsilateral IC and contralC and the AC target the matrix. In addition to GAD67, the modules are enriched in PV, AChE, $C 0$, and NADPH- $d$, whereas the matrix region contains calretinin neurons. Right, Findings from the current study. Local input patterns are highly cell type-specific, with an overall flow of information from the matrix to modular regions (small green and black arrows). The two compartments of the LCIC project to distinct targets: the modules send a purely excitatory projection to the mMGB (large black arrow). Excitatory cells in the matrix send information to the SC, ipsilateral IC, and contralC (large black arrows), whereas inhibitory matrix cells project to the ipsilateral IC (large green arrow). PV, Parvalbumin; CO, cytochrome oxidase; NADPH-d, NADPH-diaphorase; CR, calretinin; SScx, somatosensory cortex; DCoN, dorsal column nuclei.

Potential functional significance of module outputs

The mMGB is the only target of cells residing in modules that has been identified thus far. Similar to the LCIC, this division of the auditory thalamus is known to integrate multisensory inputs, and neurons in this region exhibit broad frequency tuning and large tactile receptive fields (Aitkin, 1973; Bordi and LeDoux, 1994). The mMGB is also interconnected with limbic structures, such as the amygdala, and has been shown to be involved with auditory fear conditioning (LeDoux et al., 1984, 1985). Although it has traditionally been thought that the IC provides auditory input to the mMGB, it is possible that the inputs from modules of the LCIC actually provide multisensory information important for executing conditioned fear behaviors (Ledoux et al., 1987).
The mMGB is also reciprocally interconnected with all regions of the $\mathrm{AC}$, and it has previously been hypothesized to serve as a site for multisensory integration and/or to modulate the AC based on state of arousal (Rouiller et al., 1989; Winer, 1992). Inputs from the LCIC to the mMGB could therefore convey somatosensory, auditory, or multisensory cues relevant to the animal's state of arousal. Somatosensory convergence occurs at multiple stations within the auditory system, and has generally been thought to mediate cancellation of self-generated sounds (Wu et al., 2015). The potential participation of the LCICmMGB-AC circuit in this process is intriguing given that (1) non-GABAergic module cells in the LCIC, such as those that project to the $\mathrm{mMGB}$, receive strong module-based inhibition that could be driven by extrinsic somatosensory inputs; and (2) 
inhibiting this population of projection neurons could effectively prevent activation of auditory cortical networks and conscious awareness of self-generated noise, given that the mMGB projects widely to all areas of the AC (Rouiller et al., 1989; Winer, 1992).

\section{Potential functional significance of matrix outputs}

Cells in matrix regions of the LCIC project to at least two distinct targets: the SC and other regions of the IC. It is presently unknown whether these projection systems are formed by different groups of cells or whether single cells project to both targets. Projections from the LCIC to the SC have long been thought to mediate various acoustico-motor behaviors (Huffman and Henson, 1990). For example, stimulation of the IC causes movement of the pinna and eyes in conjunction with activation of auditory neurons in the SC, and this pathway is thought to mediate additional orienting and escape/defense behaviors (Syka and Straschill, 1970). Connections between the IC and the SC are also thought to be critically involved in prepulse inhibition of the acoustic startle reflex (Koch and Schnitzler, 1997). The SC is thought to receive information about auditory prepulses in an acoustic startle paradigm from the IC and routes this information to the pedunculopontine nucleus, a brainstem structure that also provides cholinergic input to modular areas of the LCIC (Swerdlow et al., 2001; Motts and Schofield, 2009; Schofield, 2010). The pedunculopontine nucleus then routes this information to the pontine reticular nucleus, where it converges with and influences the primary startle pathway (Davis et al., 1982).

Not only do matrix regions of the LCIC send input to the CNIC, but they also receive dense inputs from this region (Lesicko et al., 2016). It is therefore possible that some of the LCIC cells that project to the CNIC participate in feedback loops with the lemniscal auditory pathway. In addition to inputs from the CNIC, matrix regions of the LCIC receive descending inputs from the AC (Lesicko et al., 2016). Although descending connections from the $\mathrm{AC}$ to the IC predominately terminate in the LCIC and DCIC, their activation has been shown to cause striking shifts in the auditory response properties of cells in the CNIC (Andersen et al., 1980; Winer et al., 1998; Gao and Suga, 2000). Given that direct descending inputs to the CNIC are sparse, it is possible that these changes are mediated through connections from the LCIC to the CNIC (Stebbings et al., 2014).

\section{References}

Aitkin LM (1973) Medial geniculate body of the cat: responses to tonal stimuli of neurons in medial division. J Neurophysiol 36:275-283.

Aitkin LM, Dickhaus H, Schult W, Zimmermann M (1978) External nucleus of inferior colliculus: auditory and spinal somatosensory afferents and their interactions. J Neurophysiol 41:837-847.

Aitkin LM, Kenyon CE, Philpott P (1981) The representation of the auditory and somatosensory systems in the external nucleus of the cat inferior colliculus. J Comp Neurol 196:25-40.

Andersen RA, Snyder RL, Merzenich MM (1980) The topographic organization of corticocollicular projections from physiologically identified loci in the AI, AII, and anterior auditory cortical fields of the cat. J Comp Neurol 191:479-494.

Bordi F, LeDoux JE (1994) Response properties of single units in areas of rat auditory thalamus that project to the amygdala. Exp Brain Res 98:261274.

Caicedo A, Herbert H (1993) Topography of descending projections from the inferior colliculus to auditory brainstem nuclei in the rat. J Comp Neurol 328:377-392.

Calford MB, Aitkin LM (1983) Ascending projections to the medial geniculate body of the cat: evidence for multiple, parallel auditory pathways through thalamus. J Neurosci 3:2365-2380.
Casseday JH, Fremouw T, Covey E (2002) The inferior colliculus: a hub for the central auditory system. In: Integrative functions in the mammalian auditory pathway, pp 238-318. New York: Springer.

Chernock ML, Larue DT, Winer JA (2004) A periodic network of neurochemical modules in the inferior colliculus. Hear Res 188:12-20.

Coleman JR, Clerici WJ (1987) Sources of projections to subdivisions of the inferior colliculus in the rat. J Comp Neurol 262:215-226.

Davis M, Gendelman DS, Tischler MD, Gendelman PM (1982) A primary acoustic startle circuit: lesion and stimulation studies. J Neurosci 2:791805.

Dillingham CH, Gay SM, Behrooz R, Gabriele ML (2017) Modular-extramodular organization in developing multisensory shell regions of the mouse inferior colliculus. J Comp Neurol 525:3742-3756.

Gao E, Suga N (2000) Experience-dependent plasticity in the auditory cortex and the inferior colliculus of bats: role of the corticofugal system. Proc Natl Acad Sci USA 97:8081-8086.

Gay SM, Brett CA, Stinson JP, Gabriele ML (2018) Alignment of EphA4 and ephrin-B2 expression patterns with developing modularity in the lateral cortex of the inferior colliculus. J Comp Neurol 526:2706-2721.

Gerfen CR (1984) The neostriatal mosaic: compartmentalization of corticostriatal input and striatonigral output systems. Nature 311:461-464.

Gerfen CR (1985) The neostriatal mosaic: I. Compartmental organization of projections from the striatum to the substantia nigra in the rat. J Comp Neurol 236:454-476.

Gerfen CR (1992) The neostriatal mosaic: multiple levels of compartmental organization. In: Advances in neuroscience and schizophrenia, pp 43-59. New York: Springer.

Goldowitz D (2010) Allen reference atlas: a digital color brain atlas of the C57BL/6J male mouse. Genes Brain Behav 9:128.

Graybiel AM, Ragsdale CW (1978) Histochemically distinct compartments in the striatum of human, monkeys, and cat demonstrated by acetylthiocholinesterase staining. Proc Natl Acad Sci USA 75:5723-5726.

Huffman RF, Henson OW Jr (1990) The descending auditory pathway and acousticomotor systems: connections with the inferior colliculus. Brain Res Brain Res Rev 15:295-323.

Jain R, Shore S (2006) External inferior colliculus integrates trigeminal and acoustic information: unit responses to trigeminal nucleus and acoustic stimulation in the guinea pig. Neurosci Lett 395:71-75.

Kincaid AE, Wilson CJ (1996) Corticostriatal innervation of the patch and matrix in the rat neostriatum. J Comp Neurol 374:578-592.

Koch M, Schnitzler HU (1997) The acoustic startle response in rats: circuits mediating evocation, inhibition and potentiation. Behav Brain Res 89:3549.

LeDoux JE, Sakaguchi A, Reis DJ (1984) Subcortical efferent projections of the medial geniculate nucleus mediate emotional responses conditioned to acoustic stimuli. J Neurosci 4:683-698.

LeDoux JE, Ruggiero DA, Reis DJ (1985) Projections to the subcortical forebrain from anatomically defined regions of the medial geniculate body in the rat. J Comp Neurol 242:182-213.

Ledoux JE, Ruggiero DA, Forest R, Stornetta R, Reis DJ (1987) Topographic organization of convergent projections to the thalamus from the inferior colliculus and spinal cord in the rat. J Comp Neurol 264:123-146.

Lesicko AM, Hristova TS, Maigler KC, Llano DA (2016) Connectional modularity of top-down and bottom-up multimodal inputs to the lateral cortex of the mouse inferior colliculus. J Neurosci 36:11037-11050.

Linke R (1999) Differential projection patterns of superior and inferior collicular neurons onto posterior paralaminar nuclei of the thalamus surrounding the medial geniculate body in the rat. Eur J Neurosci 11:187203.

Llano DA, Sherman SM (2009) Differences in intrinsic properties and local network connectivity of identified layer 5 and layer 6 adult mouse auditory corticothalamic neurons support a dual corticothalamic projection hypothesis. Cereb Cortex 19:2810-2826.

Loftus WC, Malmierca MS, Bishop DC, Oliver DL (2008) The cytoarchitecture of the inferior colliculus revisited: a common organization of the lateral cortex in rat and cat. Neuroscience 154:196-205.

Motts SD, Schofield BR (2009) Sources of cholinergic input to the inferior colliculus. Neuroscience 160:103-114.

Ono M, Yanagawa Y, Koyano K (2005) GABAergic neurons in inferior colliculus of the GAD67-GFP knock-in mouse: electrophysiological and morphological properties. Neurosci Res 51:475-492. 
Petersen CC (2007) The functional organization of the barrel cortex. Neuron 56:339-355.

Rouiller E, Rodrigues-Dagaeff C, Simm G, De Ribaupierre Y, Villa A, De Ribaupierre F (1989) Functional organization of the medial division of the medial geniculate body of the cat: tonotopic organization, spatial distribution of response properties and cortical connections. Hear Res 39:127-142.

Schofield BR (2010) Projections from auditory cortex to midbrain cholinergic neurons that project to the inferior colliculus. Neuroscience 166: $231-240$.

Schwarz C, Thier P (1995) Modular organization of the pontine nuclei: dendritic fields of identified pontine projection neurons in the rat respect the borders of cortical afferent fields. J Neurosci 15:3475-3489.

Shepherd GM, Pologruto TA, Svoboda K (2003) Circuit analysis of experience-dependent plasticity in the developing rat barrel cortex. Neuron 38:277-289.

Slater BJ, Sons SK, Yudintsev G, Lee CM, Llano DA (2019) Thalamocortical and intracortical inputs differentiate layer-specific mouse auditory corticocollicular neurons. J Neurosci 39:256-270.

Stebbings KA, Lesicko AM, Llano DA (2014) The auditory corticocollicular system: molecular and circuit-level considerations. Hear Res 314: 51-59
Swerdlow N, Geyer M, Braff D (2001) Neural circuit regulation of prepulse inhibition of startle in the rat: current knowledge and future challenges. Psychopharmacology (Berl) 156:194-215.

Syka J, Straschill M (1970) Activation of superior colliculus neurons and motor responses after electrical stimulation of the inferior colliculus. Exp Neurol 28:384-392.

Tamamaki N, Yanagawa Y, Tomioka R, Miyazaki JI, Obata K, Kaneko T (2003) Green fluorescent protein expression and colocalization with calretinin, parvalbumin, and somatostatin in the GAD67-GFP knock-in mouse. J Comp Neurol 467:60-79.

Winer JA (1992) The functional architecture of the medial geniculate body and the primary auditory cortex. In: The mammalian auditory pathway: neuroanatomy, pp 222-409. New York: Springer.

Winer JA, Larue DT, Diehl JJ, Hefti BJ (1998) Auditory cortical projections to the cat inferior colliculus. J Comp Neurol 400:147-174.

Wu C, Stefanescu RA, Martel DT, Shore SE (2015) Listening to another sense: somatosensory integration in the auditory system. Cell Tissue Res 361:233-218.

Yoshimura Y, Callaway EM (2005) Fine-scale specificity of cortical networks depends on inhibitory cell type and connectivity. Nat Neurosci 8:15521559.

Zarrinpar A, Callaway EM (2006) Local connections to specific types of layer 6 neurons in the rat visual cortex. J Neurophysiol 95:1751-1761. 